\title{
PPM1D Is a Therapeutic Target in Childhood Neural Tumors
}

\author{
Jelena Milosevic ${ }^{1,2, *(\mathbb{D}}$, Diana Treis ${ }^{1}{ }^{\mathbb{D}}$, Susanne Fransson ${ }^{3} \mathbb{D}$, Gabriel Gallo-Oller ${ }^{1}$, Baldur Sveinbjörnsson ${ }^{1}$, \\ Nina Eissler ${ }^{1}$, Keiji Tanino ${ }^{4}{ }^{(D)}$, Kazuyasu Sakaguchi ${ }^{5}$, Tommy Martinsson ${ }^{3}$, Malin Wickström ${ }^{1}$, Per Kogner ${ }^{1,+}{ }^{+}$ \\ and John Inge Johnsen $1, *,+, \ddagger \mathbb{D}$
}

1 Childhood Cancer Research Unit, Department of Women's and Children's Health, Karolinska Institutet, 17177 Stockholm, Sweden; diana.treis@ki.se (D.T.); ggallo@alumni.unav.es (G.G.-O.); baldur.sveinbjornsson@uit.no (B.S.); nina.eissler@gmail.com (N.E.) malin.wickstrom@ki.se (M.W.); per.kogner@ki.se (P.K.)

2 Center for Regenerative Medicine, Massachusetts General Hospital, Boston, MA 02114, USA

3 Department of Laboratory Medicine, Institute of Biomedicine, University of Gothenburg, 41345 Gothenburg, Sweden; susanne.fransson@clingen.gu.se (S.F.); tommy.martinsson@clingen.gu.se (T.M.)

4 Laboratory of Organic Chemistry II, Department of Chemistry, Faculty of Science, Hokkaido University, Sapporo 060-0810, Japan; ktanino@sci.hokudai.ac.jp

5 Laboratory of Biological Chemistry, Department of Chemistry, Faculty of Science, Hokkaido University, Sapporo 060-0810, Japan; kazuyasu@sci.hokudai.ac.jp

* Correspondence: jmilosevic@mgh.harvard.edu (J.M.); john.inge.johnsen@ki.se (J.I.J.)

+ Senior authors with equal contribution.

$\ddagger$ Lead contact: john.inge.johnsen@ki.se.

check for updates

Citation: Milosevic, J.; Treis, D.; Fransson, S.; Gallo-Oller, G.; Sveinbjörnsson, B.; Eissler, N.; Tanino, K.; Sakaguchi, K.;

Martinsson, T.; Wickström, M.; et al. PPM1D Is a Therapeutic Target in Childhood Neural Tumors. Cancers 2021, 13, 6042. https://doi.org/ $10.3390 /$ cancers 13236042

Academic Editor: Michele Bernasconi

Received: 24 October 2021

Accepted: 25 November 2021

Published: 30 November 2021

Publisher's Note: MDPI stays neutral with regard to jurisdictional claims in published maps and institutional affiliations.

Copyright: (c) 2021 by the authors. Licensee MDPI, Basel, Switzerland. This article is an open access article distributed under the terms and conditions of the Creative Commons Attribution (CC BY) license (https:// creativecommons.org/licenses/by/ $4.0 /)$.
Simple Summary: Medulloblastoma and neuroblastoma are childhood tumors of the central nervous system or the peripheral nervous system, respectively. These are the most common and deadly tumors of childhood. A common genetic feature of medulloblastoma and neuroblastoma is frequent segmental gain or amplification of chromosome 17q. Located on chromosome 17q23.2 is PPM1D which encodes WIP1, a phosphatase that acts as a regulator of p53 and DNA repair. Overexpression of WIP1 correlates with poor patient prognosis. We investigated the effects of genetic or pharmacologic inhibition of WIP1 activity and found that medulloblastoma and neuroblastoma cells were strongly dependent on WIP1 expression for survival. We also tested a number of small molecule inhibitors of WIP1 and show that SL-176 was the most effective compound suppressing the growth of medulloblastoma and neuroblastoma in vitro and in vivo.

Abstract: Childhood medulloblastoma and high-risk neuroblastoma frequently present with segmental gain of chromosome $17 \mathrm{q}$ corresponding to aggressive tumors and poor patient prognosis. Located within the 17q-gained chromosomal segments is PPM1D at chromosome 17q23.2. PPM1D encodes a serine/threonine phosphatase, WIP1, that is a negative regulator of p53 activity as well as key proteins involved in cell cycle control, DNA repair and apoptosis. Here, we show that the level of PPM1D expression correlates with chromosome 17q gain in medulloblastoma and neuroblastoma cells, and both medulloblastoma and neuroblastoma cells are highly dependent on PPM1D expression for survival. Comparison of different inhibitors of WIP1 showed that SL-176 was the most potent compound inhibiting medulloblastoma and neuroblastoma growth and had similar or more potent effects on cell survival than the MDM2 inhibitor Nutlin-3 or the p53 activator RITA. SL-176 monotherapy significantly suppressed the growth of established medulloblastoma and neuroblastoma xenografts in nude mice. These results suggest that the development of clinically applicable compounds inhibiting the activity of WIP1 is of importance since PPM1D activating mutations, genetic gain or amplifications and/or overexpression of WIP1 are frequently detected in several different cancers.

Keywords: neuroblastoma; medulloblastoma; chromosome 17q gain; p53; WIP1; PPM1D 


\section{Introduction}

The mutational activation of proto-oncogenes or inactivation of tumor suppressor genes are essential processes during development of cancer [1]. The tumor suppressor gene, TP53, is one of the most commonly mutated genes in cancer. The p53 protein is a master regulator of cell growth and death by controlling DNA repair mechanisms, cell cycle progression and apoptosis [2]. Dysregulation of p53 results in genomic instability, uncontrolled cell division and inhibition of apoptosis [3,4]. While TP53 mutations are detected in more than $50 \%$ of adult cancers, pediatric cancers less often exhibit TP53 mutations [5]. Neuroblastoma and medulloblastoma are childhood tumors of the peripheral and central nervous system, respectively, that just like other childhood solid tumors infrequently harbor TP53 mutations [5]. However, p53 activity is commonly impaired in these tumors, and relapsed tumors demonstrate increased incidence of TP53 mutations [6,7]. This suggests that inactivation of p53 is important for tumorigenesis and that alternative mechanisms for $\mathrm{p} 53$ attenuation are operating in these childhood cancers.

Gain of chromosome $17 \mathrm{q}$ is the most common chromosomal aberration and the strongest indicator of adverse outcomes in neuroblastoma [8-12]. Genetic analyses have shown that $75-84 \%$ of primary neuroblastoma contain either whole chromosome 17 gain or segmental gain of chromosome 17q [8,12-14]. In high-risk neuroblastoma, unbalanced chromosome 17q gain is detected in $90 \%$ of the patient's tumor samples. The shortest region of chromosome 17q gain is identified as a $25 \mathrm{Mb}$-long DNA fragment (17q23.1-17qter) [13]. This chromosomal region contains several genes connected to cancers including EME1, $B R C A 1, E R B B 2, N F 1, R A D 51 C, B R I P 1, B I R C 5$ and PPM1D. Gain of chromosome 17q or isochromsome $17 \mathrm{q}$ is also the most common chromosomal aberration found in medulloblastoma [15-18]. In total, $30-50 \%$ of primary medulloblastoma contain chromosome $17 q$ gain and patients with isochromosome 17 have earlier recurrence and worse clinical outcome [19].

Located within the gained regions of $17 \mathrm{q}$ in high-risk neuroblastoma and medulloblastoma is the protein phosphatase magnesium-dependent 1 delta (PPM1D) gene, which encodes the nuclear serine/threonine phosphatase WIP1 (wild-type p53 induced) $[20,21]$. WIP1 is a key regulator of p53, ATM, CHK1/2, and other molecules important in apoptosis, cell cycle progression and DNA repair, and is thus critically involved in DNA damage response and cell cycle control [22-27]. Consistently, mutations and amplifications of PPM1D as well as overexpression of its gene product WIP1 have been seen in a wide range of malignancies [28-37]. Additionally, studies in mice have shown that enhanced expression of PPM1D increases the onset of ERBB2-induced mammary gland tumors [38] and also increases the incidence of SHH-driven medulloblastomas [39]. Conversely, PPM1D knockout mice demonstrated reduced frequencies of Apc-driven polyposis [40] and delayed E $\mu$-myc-induced B-cell lymphoma [26]. Together, these previous data suggest that PPM1D is important for tumorigenesis and constitutes a potential target for therapy.

\section{Results}

2.1. PPM1D Expression Correlates with Chromosome 17q Gains in Medulloblastoma and Neuroblastoma Cells

We examined the expression of PPM1D mRNA in a panel of cell lines, including both neuroblastoma and medulloblastoma, as well as the breast cancer cell lines MCF-7 and BT474 exhibiting PPM1D gene amplification [41], and one sPNET cell line (PSFK-1) containing isochromosome 17. The cell lines expressed different levels of PPM1D mRNA that correlated with their genomic profile $[42,43]$ with highest expression in PPM1D-amplified cell lines and lowest in those without chromosome 17 aberrations (Figure 1A,B). All neuroblastomas expressed PPM1D mRNA, and the highest expression was observed in SK-N-DZ and IMR32, showing expression levels comparable to the PPM1D-amplified breast cancer cell lines MCF-7 and BT-474 (Figure 1A). Furthermore, the relative expression level of PPM1D mRNA was higher in medulloblastoma cell lines with 17q-gained aberrations (D283-MED, D458-MED and MEB-MED8A) compared to cell lines with normal 17q (DAOY, UW228-3 
and PFSK-1), further demonstrating a gene-dosage effect on PPM1D mRNA expression (Figure $1 \mathrm{~A}, \mathrm{C})$.

A

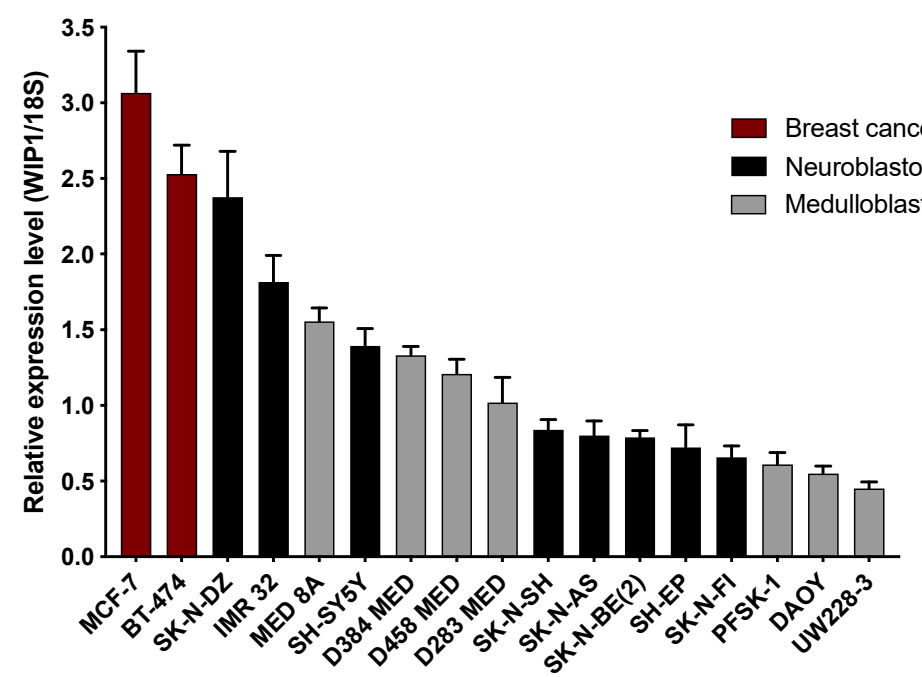

B

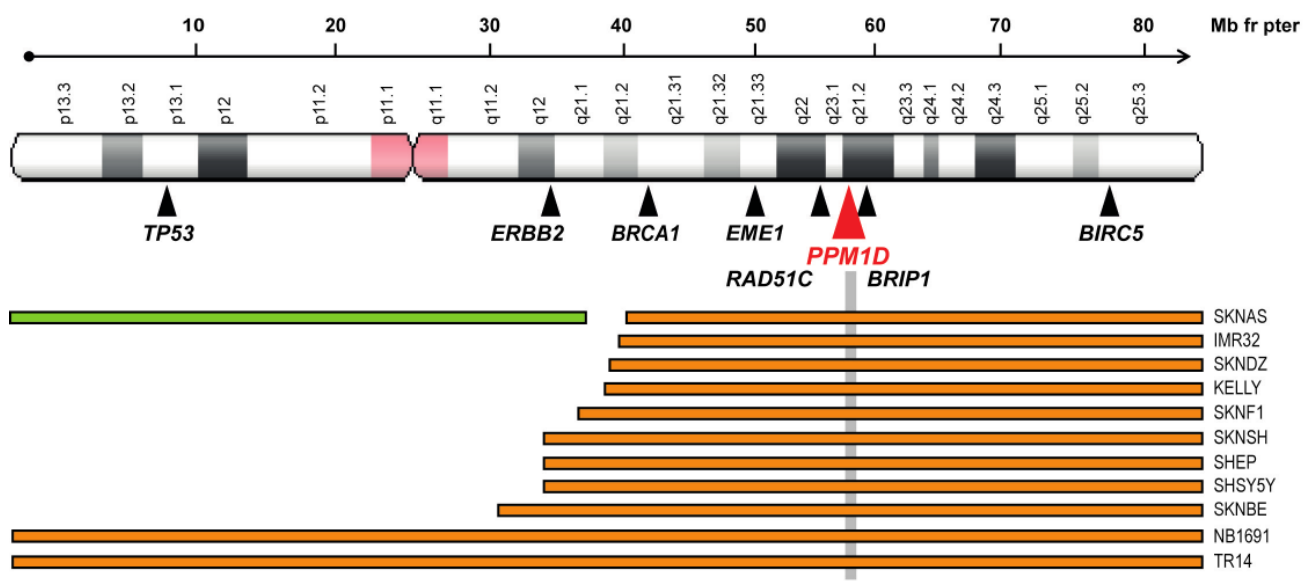

\section{C}

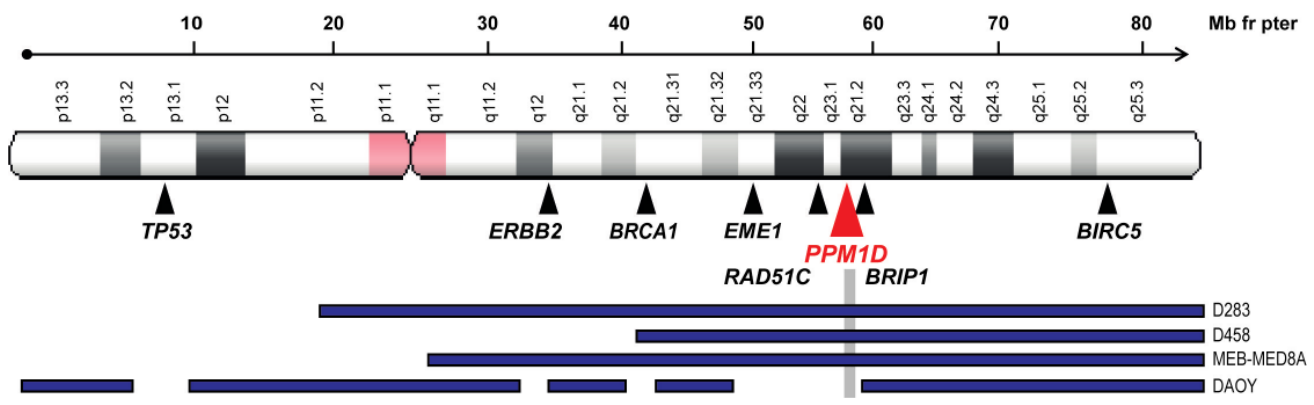

Figure 1. PPM1D expression correlates to 17q copy number gain. (A). PPM1D is expressed at different levels in neuroblastoma and medulloblastoma cell lines. Relative PPM1D mRNA expression in two PPM1D-amplified breast cancer cell lines (pink bars), eight neuroblastoma (NB) cell lines (black bars), six medulloblastoma (MB) cell lines (grey bars) and the supratentorial primitive neuroectodermal tumor (sPNET) cell line PFSK-1 (grey bar), analyzed with real-time PCR. The breast cancer cell line MCF-7 is amplified for PPM1D and used as a positive control for PPM1D mRNA expression. Means with S.D. of three experiments are displayed. (B). Chromosome 17q ploidy in neuroblastoma cell lines. Summary of whole or segmental chromosome 17 gain reported in neuroblastoma cell lines [42,43]. (C). Chromosome 17q ploidy in in medulloblastoma cell lines. See Figure S1 for details. 


\subsection{PPM1D Dependency in Medulloblastoma and Neuroblastoma}

We next used genome-scale CRISPR-Cas9 screening [44], and demonstrated that TP53 wild-type neuroblastoma cell lines displayed a higher genetic dependency of PPM1D as compared to TP53 mutated cell lines (Figure 2A,B and Table S1). Other TP53-repressing regulators such as $M D M 2, M D M 4$ and $U S P 7$ were ranked as number 3, 21 and 31, respectively. Among the top 40 ranked genes with the largest difference between wild-type and mutated TP53, an enrichment of genes involved in the negative regulation of cell proliferation (FDR $=0.0117$ ), cell cycle process ( $F D R=0.0117)$, cellular response to DNA damage (FDR $=0.05)$ and chromosome organization $(\mathrm{FDR}=0.05)$ (Figure $2 \mathrm{C})$ was evident.

Focusing on PPM1D, MDM2, MDM4 and USP7, for all of which pharmacological inhibitors are in preclinical testing or clinical trials, we showed that neuroblastoma cell lines have preferential dependency for all four genes in TP53 wild-type cell lines (Figure 2D). In cell lines of medulloblastoma origin, MDM2 showed the largest difference in dependency score with negative regulators $P P M 1 D, U S P 7$ and MDM4, ranked 6, 41 and 64, respectively (Figure 2A,B).

Among the top 40 genes ranked according to the largest difference between wild-type and mutated TP53, there is a functional enrichment of pathways associated with cell cycle $(\mathrm{FDR}=0.000119)$, chromosome organization $(\mathrm{FDR}=0.00065)$ and nucleotide biosynthesis processes $(F D R=0.003)$ (Figure $2 C)$. As expected from the ranked differences between wildtype and mutated TP53 medulloblastomas, only PPM1D and MDM2 showed differences in genetic dependency (Figure 2D).

A

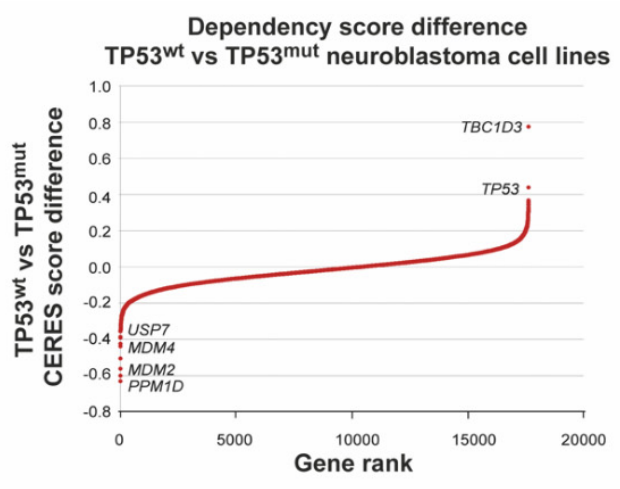

B

Dependency score distribution NB cell lines

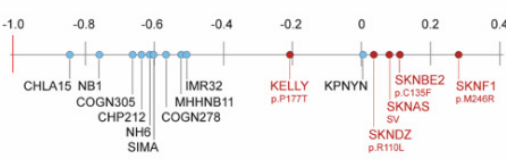

C

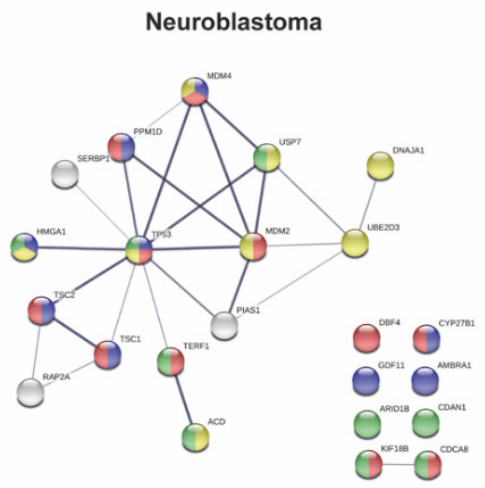

Dependency score difference

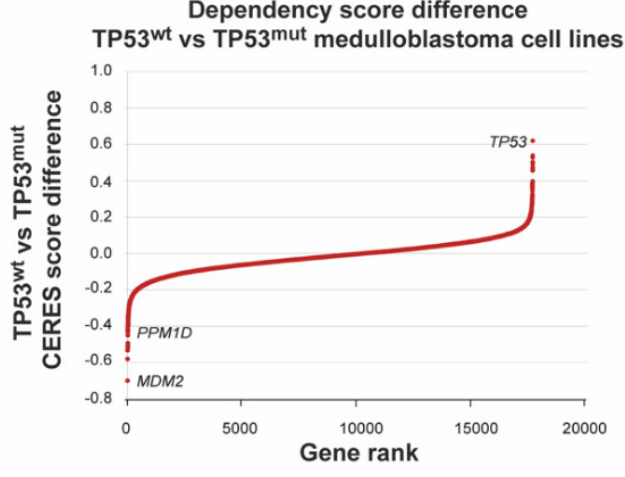

Dependency score distribution MBL cell lines

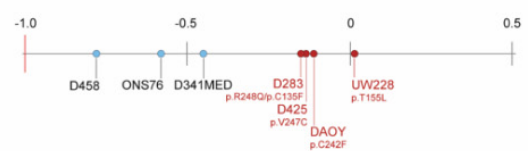

Medulloblastoma

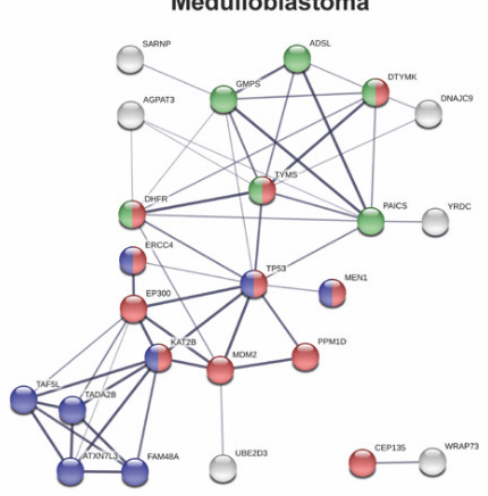

Figure 2. Cont. 
D

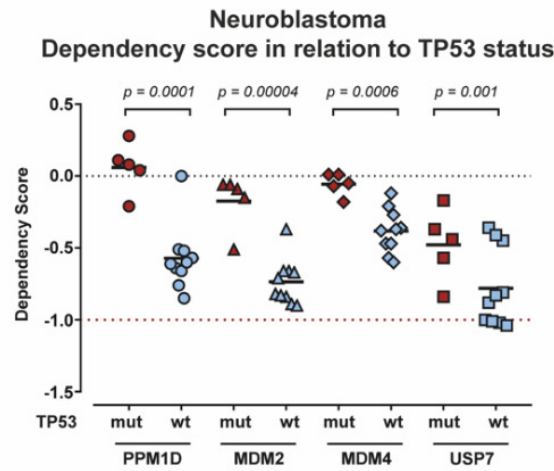

Medulloblastoma

Dependency score in relation to TP53 status

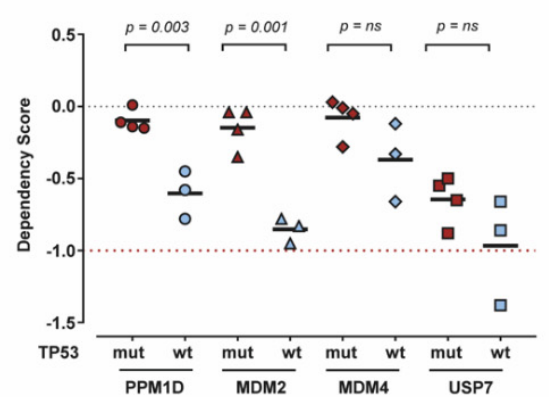

E

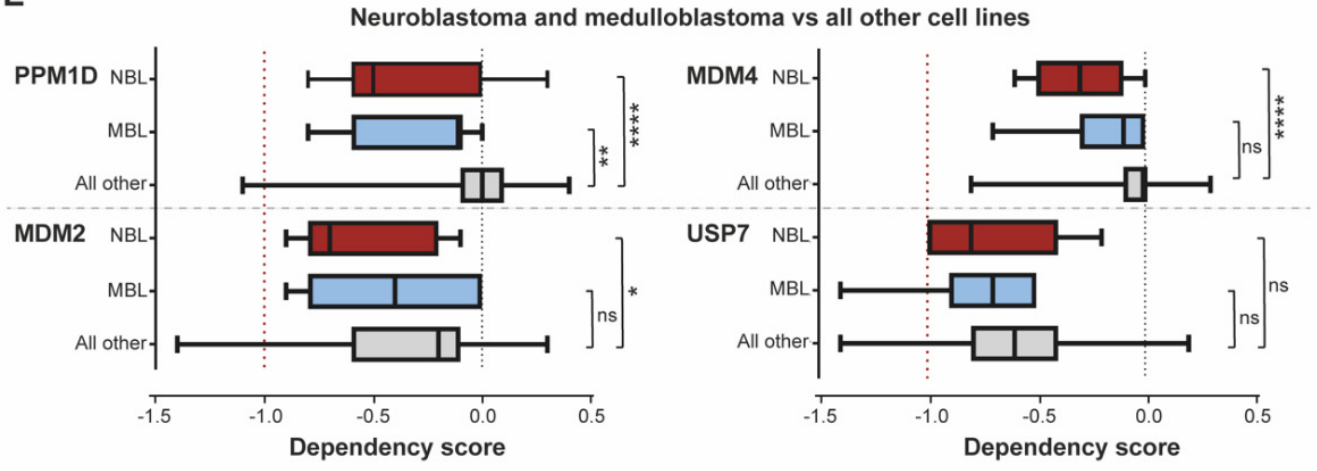

Figure 2. PPM1D expression is important for neuroblastoma and medulloblastoma survival. (A) Genome-scale CRISPRCas9 screening showing ranked average difference in genetic dependencies between wild-type TP53 and mutated TP53 neuroblastoma and medulloblastoma cell lines. (B) Dependency score showing high PPM1D dependency in wild-type TP53 neuroblastoma and medulloblastoma cells. Wild-type TP53 cell lines (blue, high dependency) and TP53-mutated cell lines (red, low dependency) with TP53 status. (C) STRING database analysis showing PPM1D dependency in wild-type TP53 neuroblastoma and medulloblastoma cells. Among the top 40 genes with the largest differences in gene dependency, as expressed as CERES scores, there was an enrichment of genes involved in the negative regulation of cell proliferation (indicated in blue), cell cycle process (red), cellular response to DNA damage (yellow) and chromosome organization (green). The width of the edges corresponds to the level of confidence (medium confidence STRING scores of 0.4; high confidence STRING score 0.7; and highest confidence STRING score 0.9). (D) Wild-type TP53 neuroblastoma and medulloblastoma cells are highly dependent on PPM1D expression for survival. Genome-scale CRISPR-Cas9 screening showing ranked average differences in genetic dependencies between wild-type vs. TP53-mutated cell lines. (E) Dependency scores of PPM1D, MDM2, MDM4, and USP7 in relation to TP53 mutational status in neuroblastoma and medulloblastoma cell lines. For $P P M 1 D$, there was a statistically significantly stronger genetic dependency in neuroblastoma and medulloblastoma cells as compared with all other cell lines. ${ }^{*} p<0.05,{ }^{* *} p<0.01,{ }^{* * * *} p<0.0001$.

When comparing the genetic vulnerability of PPM1D, MDM2, MDM4 and USP7 in neuroblastoma and medulloblastoma cell lines to all the other cancer cell lines in the CRISPR Avana dataset, PPM1D showed strong selective dependency in both neuroblastoma and medulloblastoma (Figure 2E), highlighting the essentiality of intact p53.

\subsection{Downregulation of PPM1D Expression Impairs Growth and Sensitizes Medulloblastoma and Neuroblastoma Cells to Irradiation}

To study the potential tumorigenic function of PPM1D/WIP1 in neuroblastoma and medulloblastoma, we next used genetic manipulation through the stable knockdown of short-hairpin RNA (shRNA) against PPM1D. The majority of neuroblastoma and medulloblastoma cell lines transfected with PPM1D shRNA were non-viable compared to scrambled controls (data not shown), whereas cells that were viable after transfection showed reduced proliferation and increased $\mathrm{H} 2 \mathrm{AX}$ phosphorylation, suggesting an effect on cell viability and genomic integrity (Figures 3A and S2). The multi-resistant neuroblastoma cell line SK-N-BE(2), isolated from a patient with recurrent stage 4 neuroblastoma, was chosen 
for further analysis, since this was one of the few cell lines that was viable after PPM1D shRNA knockdown.

A

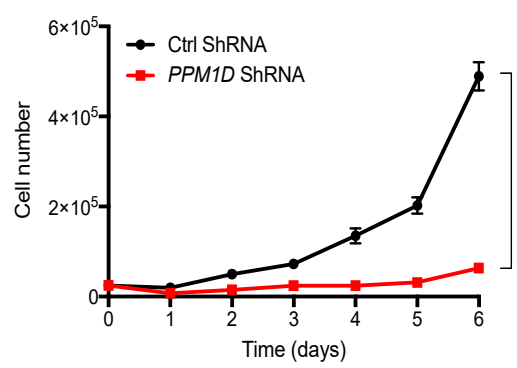

D PPM1D

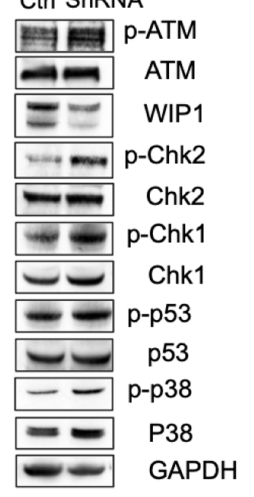

$\mathrm{F}$

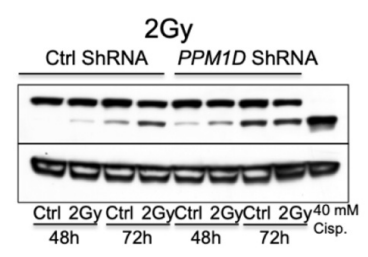

B

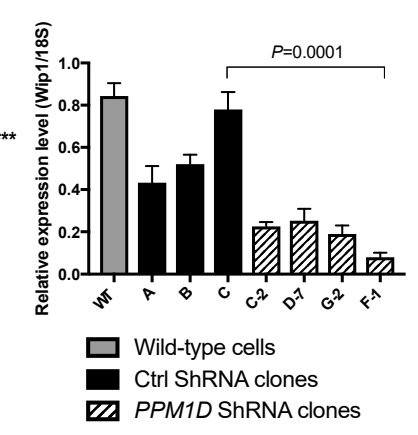

C

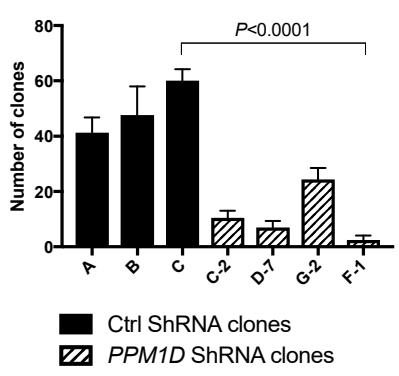

$E$

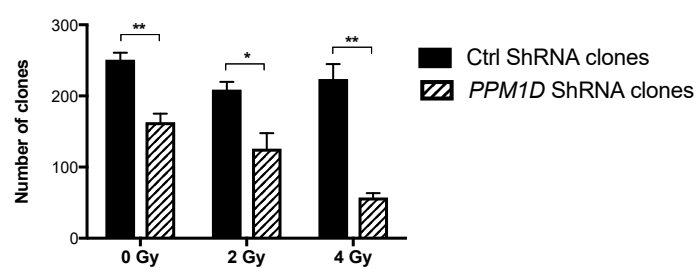

G
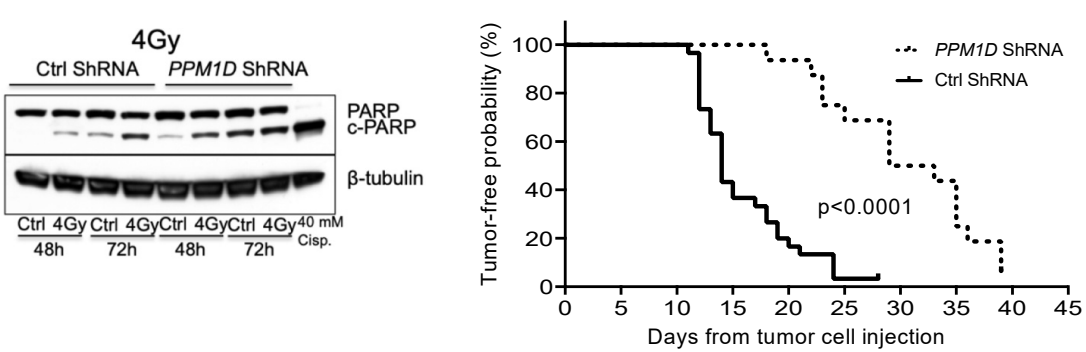

Figure 3. Inhibition of PPM1D expression suppresses tumorigenic capacity and sensitizes neuroblastoma cells to irradiation. (A) Knockdown of PPM1D with shRNA impairs proliferation of neuroblastoma cell line SK-N-BE(2). Mean with S.D. of three independent experiments is shown ( $t$-test day $6,{ }^{* * *} p<0.001$.) (B) Normalized PPM1D mRNA expression in wild-type SK-N-BE(2) cells (grey bar) compared to three clones transfected with a non-silencing control shRNA (black bars, A-C) and four different PPM1D shRNA knockdown clones (hatched bars, C-2, D-7, G-2 and F-1). The expression of PPM1D mRNA was significantly lower in the clones transfected with the different PPM1D shRNAs compared to the control transfected clones (one-way ANOVA with Bonferroni correction $p<0.05$ ). Mean with S.D. of three determinants is shown. (C) Knockdown of PPM1D inhibits colony-forming ability of neuroblastoma cells. Clonogenic assay of SK-N-BE(2) cells showing decreased colony formation in shRNA PPM1D knockdown cells (one-way ANOVA with Bonferroni post-test $p<0.0001)$ with lowest colony-forming ability in the F-1 clone ( $t$-test $p<0.0001)$. Mean with S.D. of nine determinants is displayed. (D) Knockdown of PPM1D inhibits dephosphorylation of WIP1 target genes. Phosphorylation levels of WIP1 targets increased after PPM1D knockdown (clone F-1) compared to control transfected cells (clone C), as shown by Western blotting. (E) PPM1D downregulation sensitizes neuroblastoma cells to irradiation. PPM1D knockdown of SK-N-BE(2) cells showed an irradiation dose-dependent decrease in clonogenic capacity compared to control transfected cells. Mean with S.D. of three experiments ( $t$-test, $\left.{ }^{*} p<0.05,{ }^{* *} p<0.01\right)$. (F) ShRNA-mediated knockdown of PPM1D increases irradiation-induced apoptosis. Protein expression of the pro-apoptotic marker cPARP in PPM1D knockdown cells compared to control transfected cells 48 and $72 \mathrm{~h}$ after exposure to irradiation, analyzed by Western blot. $\beta$-tubulin was used as protein loading control. Cisplatin was used as positive control. (G) Knockdown of PPM1D delays neuroblastoma 
development. Clone F-1 and control clone $\mathrm{C}$ were injected subcutaneously in NMRI $n u / n u$ mice (shRNA, $n=8$; control, $n=15), 5$ million cells bilaterally. Tumor development was significantly delayed (log-rank test $p<0.0001)$ showing median time to tumor development (defined as tumor volume $\geq 0.1 \mathrm{~mL}$ ) to be more than doubled (33 days vs. 15 days) after PPM1D downregulation (dashed line) compared to animals injected with cells transfected with the non-silencing control shRNA (black line).

Analyzing different shRNAs constructs directed against PPM1D mRNA in SK-N-BE(2) cells established PPM1D-shRNA F-1 as the most effective in reducing PPM1D mRNA levels (Figure 3B). In concordance, all PPM1D-shRNA clones displayed impaired clonogenic capacity compared to the control shRNA clones (Figure 3C). PPM1D knockdown was also confirmed by increased phosphorylation of WIP1 target proteins including ATM, CHK1, CHK2, p53 and p38, all involved in cell cycle regulation and the DNA-damage response (DDR) (Figures 3D and S4).

To test the role of PPM1D in cellular stress, we next subjected SK-N-BE(2) cells to irradiation, and showed that cells lacking PPM1D exhibited increased sensitivity to irradiation compared to control cells (Figures 3E and S4). Moreover, higher levels of PARP cleavage were detected in PPM1D shRNA-transfected cells compared to controls, suggesting an increased vulnerability to apoptosis following irradiation (Figure $3 \mathrm{~F}$ ).

Furthermore, to evaluate the effect of PPM1D knockdown on tumor development in vivo, SK-N-BE(2) cells with either PPM1D-knockdown or control shRNA were injected subcutaneously in mice and tumor growth was compared. Tumor development was significantly delayed with median time to tumor development ( $\geq 0.1 \mathrm{~mL}$ tumor volume) more than doubled (33 days median, vs. 15 days) in the PPM1D-shRNA knockdown group compared to animals injected with control shRNA-transfected cells $(p<0.001)$ (Figure 3G).

\subsection{Pharmacological Targeting of WIP1 Impairs Medulloblastoma and Neuroblastoma Growth}

Having established that $P P M 1 D$-knockdown reduces tumor formation in mice and that gain of chromosome 17q harboring PPM1D is a strong prognostic factor for poor survival in both neuroblastoma and medulloblastoma [45,46], we next investigated the effects of compounds inhibiting WIP1 activity in both cancers.

To assess the cytotoxic effects of different WIP1 inhibitors on cell viability, six neuroblastoma cell lines and the PPM1D-amplified breast cancer cell line MCF-7 were exposed to different concentrations of the WIP1 inhibitors SL-176, SPI-001, CCT007093 or GSK2830371 [47-51]. Treatment of neuroblastoma cell lines with the specific WIP1-inhibitor SL-176 achieved complete inhibition with $\mathrm{IC}_{50}$ values within a rather narrow range of 0.57-1.3 $\mu \mathrm{M}$, regardless of $\mathrm{p} 53$ or MDM2 status (Figures 4A, S3A and Table S2A). The WIP1 inhibitors SPI-001 and CCT007093 did not reach complete inhibition at the concentrations tested, and the $\mathrm{IC}_{50}$ values spanned from 1.0 to $>25 \mu \mathrm{M}$ and 27 to $48 \mu \mathrm{M}$, respectively. Additionally, for these two WIP1 inhibitors, sensitivity of neuroblastoma cells did not cluster according to p53 or MDM2 status. For the WIP1 inhibitor GSK2830371 the $\mathrm{IC}_{50}$ values ranged from 0.25 to $26 \mu \mathrm{M}$, where the p53 wild type (SH-SY5Y) was the most sensitive and the p53 mutated cell lines (SK-N-AS, SK-N-BE(2)) showed more resistance. Among the WIP1 inhibitors tested, SL-176 displayed the lowest mean $\mathrm{IC}_{50}$, with a significantly lower IC 50 than SPI-001 and CCT007093 $(p<0.001)$; however, no significant difference was observed between the mean $\mathrm{IC}_{50}$ values of SL-176 and GSK2830371. 
A

B

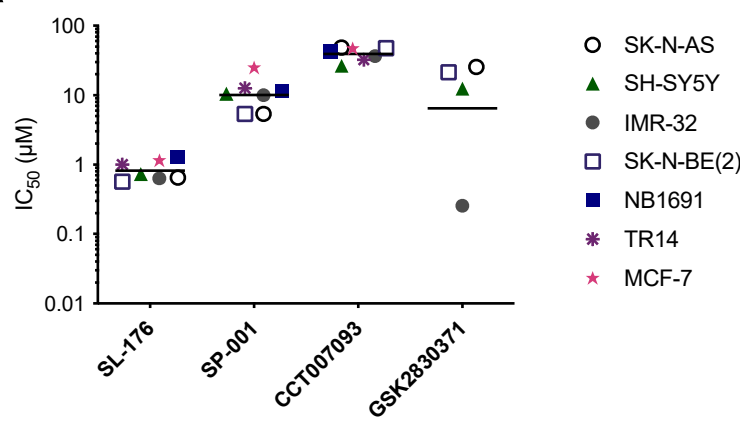

C

○ SK-N-AS

- SK-N-SH

$\checkmark$ SH-EP

A SH-SY5Y

- Kelly

- IMR-32

口 SK-N-BE(2)

$\triangle$ SK-N-DZ

$\nabla$ SK-N-FI

- NB1691

* TR14

* MCF-7

+ MRC-5

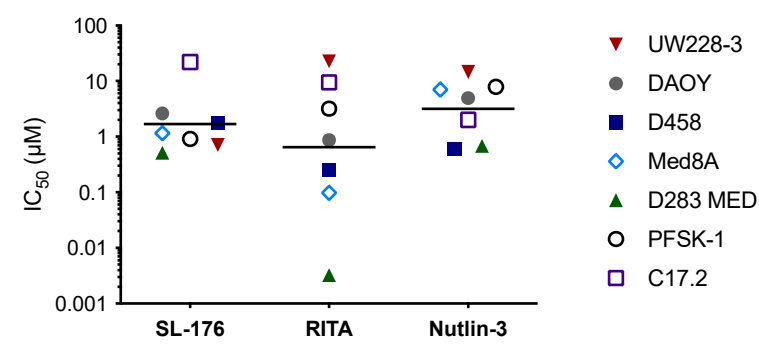

D

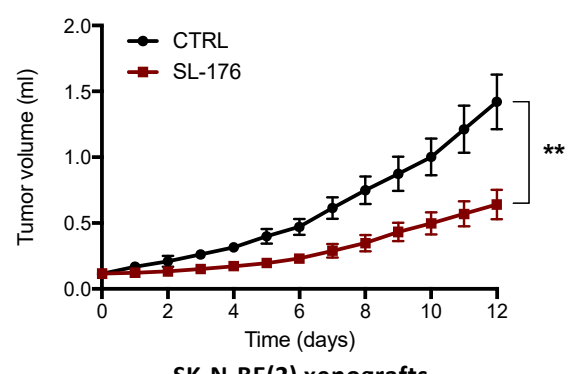

SK-N-BE(2) xenografts

E

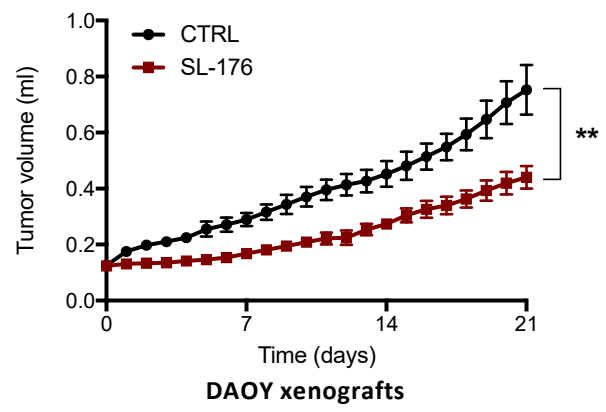

F SK-N-BE(2) xenografts
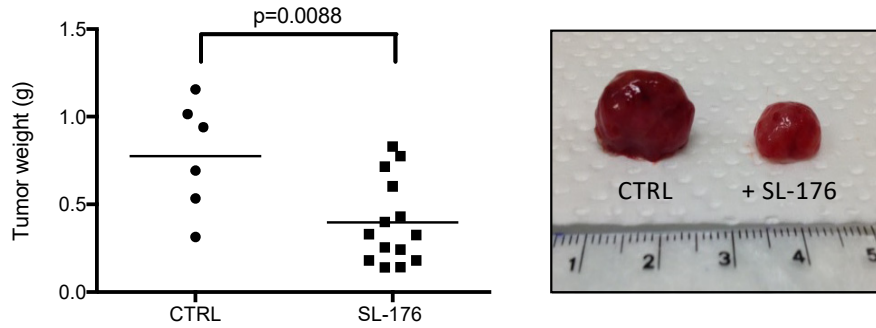

Figure 4. Cont. 
G

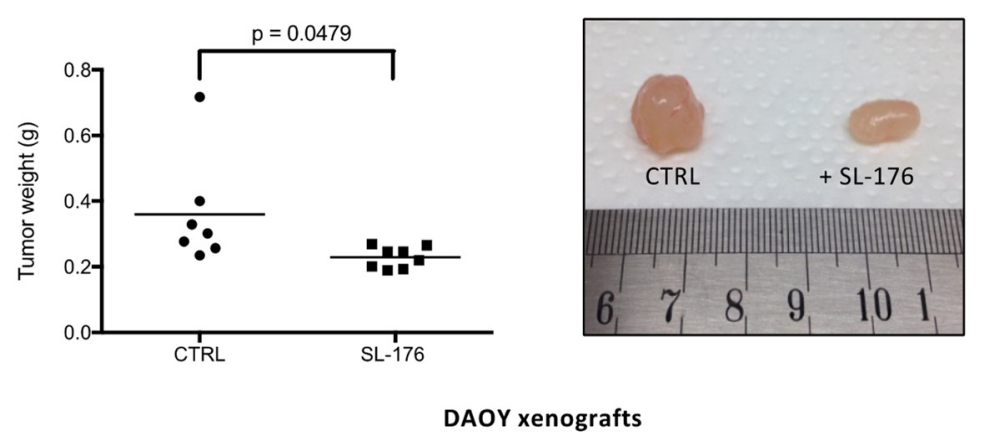

$\mathrm{H}$

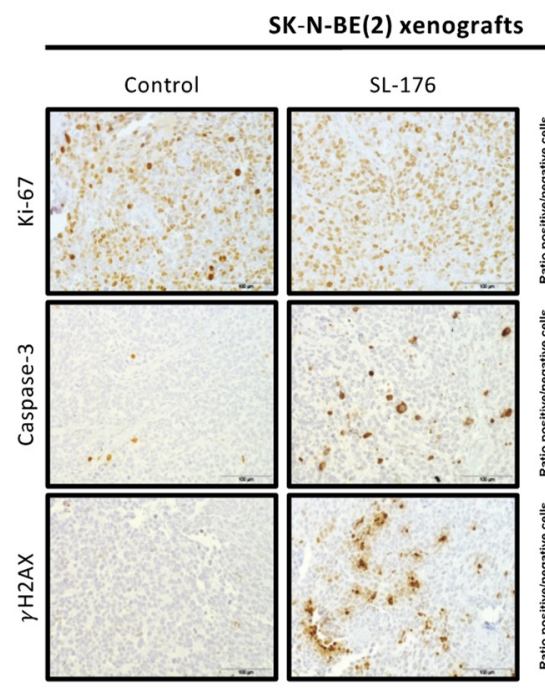

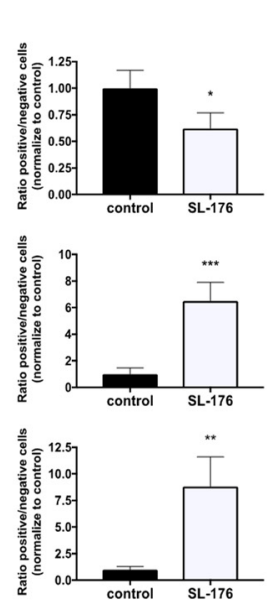

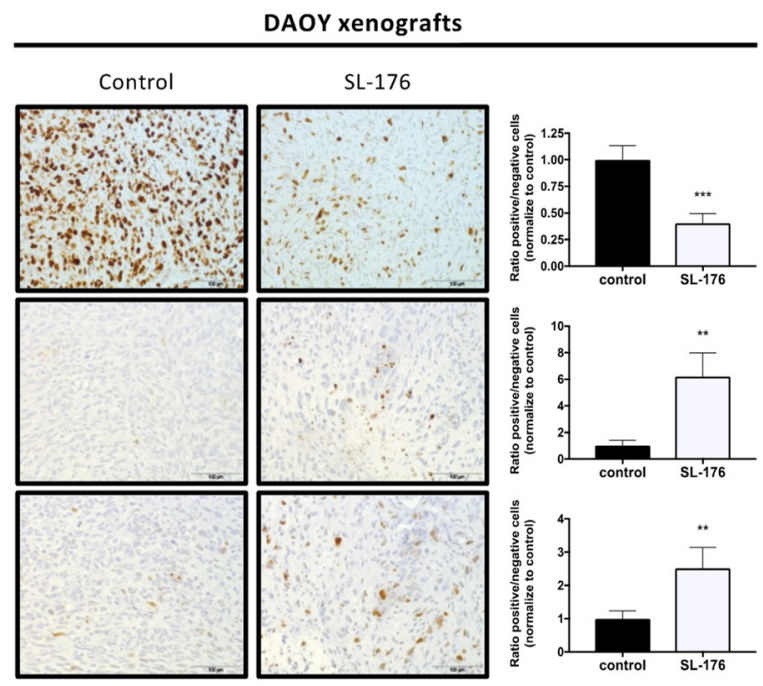

Figure 4. The WIP1 phosphatase inhibitor SL-176 suppresses neuroblastoma and medulloblastoma growth in vitro and in vivo. (A) SL-176 is more or equally efficient in inhibiting tumor cell viability among the WIP1 inhibitors tested. IC 50 values for four to six neuroblastoma cell lines and the PPM1D-amplified breast cancer cell line MCF-7 exposed to the WIP1 inhibitors SL-176, SPI-001, CCT007093 and GSK2830371. Horizontal lines indicate mean. IC 50 values were calculated from cell viability assays performed at least three times. SL-176 displayed a lower mean of IC $_{50}$ values than SPI-001 and CCT007093, while no difference was observed when comparing with GSK2830371 (mixed effects model on log IC 50 $p<0.0001$, Bonferroni post-test: SL-176 vs. SPI-001 $p<0.0001$, SL-176 vs. CCT007093 $p<0.0001$, SL-176 vs. GSK2830371 $p=0.74$ ). (B) SL-176 is an efficacious inhibitor of neuroblastoma cell viability. $\mathrm{IC}_{50}$ values for eleven neuroblastoma cell lines, the breast cancer cell line MCF-7 and the fibroblast cell line MRC-5 exposed to the specific WIP1 inhibitor SL-176, the p53-MDM2 interaction inhibitor RITA or the MDM2 antagonist Nutlin-3. Horizontal lines indicate mean. SL-176 displayed the lowest mean of $\mathrm{IC}_{50}$ values in the neuroblastoma cell lines of the three tested compounds (mean $\mathrm{IC}_{50}$ for SL-176: 0.77 $\mu \mathrm{M}$; RITA: $2.0 \mu \mathrm{M}$; and Nutlin-3: $3.7 \mu \mathrm{M}$ ); however, a significant difference was only evident between SL-176 and Nutlin-3 (repeated measures one-way ANOVA on $\log \mathrm{IC}_{50} p=0.030$, Bonferroni post-test SL-176 vs. Nutlin-3 $p=0.0088$, SL-176 vs. RITA $p=0.14)$. IC 50 values were calculated from the results of the cell viability assay WST-1 performed at least three times. (C) SL-176 inhibits medulloblastoma cell viability. IC $_{50}$ values for five medulloblastoma cell lines, the supratentorial primitive neuroectodermal (sPNET) tumor cell line PFSK-1 and the murine neural progenitor cell line C17.2 exposed to the specific WIP1 inhibitor SL-176, the p53-MDM2 interaction inhibitor RITA or the MDM2 antagonist Nutlin-3. Horizontal lines indicate mean. No significant differences between the mean $\mathrm{IC}_{50}$ values were shown in these medulloblastoma cell lines (mean IC $_{50}$ for SL-176: $1.3 \mu \mathrm{M}$, RITA: $1.1 \mu \mathrm{M}$ and Nutlin-3: $4.7 \mu \mathrm{M}$, repeated measures one-way ANOVA $p=0.10$ ). IC 50 values were calculated from the results of the cell viability assay WST-1 performed at least three times. MRC-5 and C17.2 were used as a non-tumorigenic control for drug toxicity. (D,E) SL-176 inhibit neuroblastoma (D) and medulloblastoma (E) growth in vivo. Nude mice were injected with neuroblastoma SK-N-BE(2) cells to form xenografts on the flank. Daily i.p. injections of SL-176 $(n=14)$ for 12 days, starting at tumor volume $0.1 \mathrm{~mL}$, compared to no treatment $(\mathrm{CTRL}, n=6)$ showed 
that WIP1 inhibition through SL-176 significantly impaired the growth of neuroblastoma xenografts $(t$-test day $12, p=0.002)$. Nude mice engrafted with medulloblastoma DAOY xenografts were treated from tumor volume $0.12 \mathrm{~mL}$, receiving either daily i.p. injections of SL-176 $(n=8)$ for 21 days or no treatment $(n=7)$. SL-176 treatment significantly delayed medulloblastoma xenograft growth ( $t$-test day 21, $p=0.0051)$. Mean with S.E.M. (F,G) Tumor weight at autopsy of SK-N$\mathrm{BE}(2)(\mathbf{F})$ and DAOY $(\mathbf{G})$ xenografts and representative photographs of dissected neuroblastoma and medulloblastoma xenograft tumors in comparison. (H,I) SL-176 decreases proliferation, induces apoptosis and activates $\gamma \mathrm{H} 2 \mathrm{AX}$ in xenograft tumors. Immunohistochemical analysis of SK-N-BE(2) (H) and DAOY (I) xenograft tumors. Tumor sections were stained with anti-Ki-67, anti-Caspase 3, and anti- $\gamma \mathrm{H} 2 \mathrm{AX}$ antibodies. Representative examples of immunostainings are shown. Images were acquired at $400 \times$ magnification. Identification and quantification of positive and negative cells was carried out with ImageJ software $\left(t\right.$-test, $\left.{ }^{*} p<0.05,{ }^{* *} p<0.01,{ }^{* * *} p<0.001\right)$.

To compare the effect of WIP1 inhibition with the effect of alternative indirect p53 reactivation, a panel of eleven neuroblastoma and six medulloblastoma/sPNET cell lines were treated with different concentrations of SL-176, the p53 modulator RITA, and the MDM2 antagonist Nutlin-3. The breast cancer cell line MCF-7 and two non-cancerous cell lines-MRC-5 derived from human fetal lung fibroblasts and C17.2 derived from murine neural progenitor cells-were also included in the screening (TP53 status is shown in Table S3). SL-176 again displayed a narrow span of $\mathrm{IC}_{50}$ values of $0.44-1.3 \mu \mathrm{M}$ and was more efficient than Nutlin-3 and as potent as RITA against the neuroblastoma cell lines (mean IC $_{50}$ for SL-176: $0.77 \mu \mathrm{M}$, RITA: $2.0 \mu \mathrm{M}$ and Nutlin-3: $3.7 \mu \mathrm{M}$ ) (Figures 4B, S3B and Table S2B). Neuroblastoma cell line sensitivity toward RITA spread between IC $_{50}$ values 0.19 and $>50 \mu \mathrm{M}$ without any apparent clustering according to known cell line genetics, while sensitivity toward Nutlin-3 tended to be greater among TP53 wild-type neuroblastoma cell lines, with $\mathrm{IC}_{50}$ ranging between 0.47 and $16 \mu \mathrm{M}$ (Figures $4 \mathrm{~B}, \mathrm{~S} 3 \mathrm{~B}$ and Table S2B).

For medulloblastoma and sPNET cell lines, SL-176 had similar effects on viability as the p53 inhibitors RITA and Nutlin-3. However, no significant differences between the mean $\mathrm{IC}_{50}$ values in medulloblastoma cell lines were observed (mean $\mathrm{IC}_{50}$ for SL-176: $1.1 \mu \mathrm{M}$, RITA: $0.41 \mu \mathrm{M}$ and Nutlin-3: $3.4 \mu \mathrm{M} ; p=0.26$ ) (Figures $4 \mathrm{C}$, S3B and Table S2B). All three drugs achieved complete inhibition of most cell lines tested (Figure S3B). The non-cancerous cell lines MRC-5 and C17.2 were less sensitive to SL-176 than the cancer cell lines ( $\mathrm{IC}_{50}$ for SL-176: 2.8 and $22 \mu \mathrm{M}$, RITA: $>50$ and $9.5 \mu \mathrm{M}$ and Nutlin-3: 5.3 and $1.0 \mu \mathrm{M}$ ) (Figures 4B,C, S3B and Table S2B).

Having established SL-176 as the most potent inhibitor of the WIP1-MDM2-p53 circuit among the compounds tested, we next investigated the anti-tumorigenic effect of SL-176 monotherapy in preclinical in vivo models of neuroblastoma and medulloblastoma. Tumor growth inhibition was observed after one day of treatment (SK-N-BE(2); $p=0.01$, DAOY; $p=0.02$ ) (Figure 4D,E). Both tumor volume and weight at the end of the experiment were significantly smaller in SL-176-treated mice compared to control mice (SK-N-BE(2); $p<0.01$, DAOY; $p<0.05$ ) (Figure 4F,G). No adverse effects of SL-176 were observed in the treatment groups. Histologically, SL-176-treated tumors showed an increase in active caspase- 3 and phosphorylation of the DNA repair protein $\gamma \mathrm{H} 2 \mathrm{AX}$, whereas reduced levels of the proliferation marker Ki-67 were observed (Figure 4H,I).

\section{Discussion}

Neuroblastoma and medulloblastoma are childhood tumors of the developing peripheral and central nervous system, respectively, which despite intensified multimodal therapy still have a poor outcome when compared to pediatric cancers in general. In order to improve management, clinical care and the chance of a cure for these patients, a detailed molecular understanding of the diseases and the development of new therapies based on this understanding are essential. A common genetic feature of neuroblastoma and medulloblastoma is segmental gain of chromosome $17 q$, which in both diseases is a predictor of poor prognosis $[8,45,52]$. Frequent gain of chromosome $17 \mathrm{q}$ is also observed in cancers with epithelial, neural or hematopoietic origin [53-58]. This suggests that one or 
multiple genes important for tumorigenesis are located on 17q. Several cancer-associated genes have been identified on chromosome 17q, including PPM1D, EME1, BRCA1, ERBB2, NF1, RAD51C, BRIP1 and BIRC5. Given the importance of PPM1D as a key regulator of cellular responses to DNA damage, as well as the frequent detection of gene mutations, gains or amplifications of PPM1D in various cancers resulting in the overexpression of WIP1 or the expression of truncated, oncogenic versions of WIP1 proteins $[33,37,59,60]$, PPM1D stands out as a strong candidate for tumorigenic involvement.

To functionally test the importance of PPM1D in neuroblastoma and medulloblastoma, we investigated the effects of genetic or pharmacological inhibition of WIP1 and demonstrated that blocking the expression or activity of WIP1 suppressed both neuroblastoma and medulloblastoma growth in vivo. These findings, together with similar observations $[34,61,62]$, further support that WIP1 is important for the development and progression of these neural tumors. WIP1 is a homeostatic regulator of the DNA damage response (DDR) cascade by dephosphorylation and inactivation of ATM, ATR, CHK1, CHK2 and DNA-dependent protein kinase catalytic subunit $[63,64]$. Expression of WIP1 is directly guided by 553 acting as a transcription factor on elements within the $5^{\prime}$-untranslated region of the PPM1D gene [20]. This autoregulatory loop results in WIP1-mediated dephosphorylation of p53 (Ser15) and p53 inactivation. WIP1 also dephosphorylates and inactivates the p53-activating kinases ATM, CHK1 and CHK2, which phosphorylate p53 at Ser15 and Ser20, respectively [22-24,26,65]. These dephosphorylation events allow MDM2 to interact with p53 and mediate proteasomal degradation [38]. This and concurrent WIP1-mediated inactivation of p53 will reduce the fidelity of overall DNA repair mechanisms and promote the accumulation of DNA aberrations, which is a prerequisite for tumorigenesis [5]. Accordingly, we observed increased phosphorylation of DDR proteins and H2AX, enhancing the sensitivity to irradiation of PPM1D knockdown neuroblastoma cells. Additionally, phosphorylation of p53 (Ser15) was increased in PPM1D knockdown cells. Although mutations of TP53 are not commonly detected at time of diagnosis in neuroblastoma or medulloblastoma, the p53 activity is recurrently compromised in these tumors [52,66-69], and p53 inactivation has been shown to contribute significantly to neuroblastoma and medulloblastoma development in specific animal models [70-72]. Our results indicate that p53 activity is restored in cells expressing low or no WIP1. We also tested the anti-tumorigenic effect of four WIP1 inhibitors, SL-176, SPI-001, CCT007093 and GSK2830371 [47-51], as well as the p53 modulators RITA and Nutlin-3 [73,74]. Among these compounds, SL-176 was the most universally potent compound in inducing cytotoxicity across different neuroblastoma cell lines and had cytotoxic effects similar to RITA and Nutlin-3 in medulloblastoma cells.

The WIP1 inhibitor SL-176 was developed as a simplified analog of SPI-001 and has been shown to inhibit the phosphatase activity of WIP1 by noncompetitive inhibition [49,51]. SL-176 displays an inhibitory profile which deviates from the one seen in the allosteric WIP1 inhibitor GSK2830371: while the latter exhibits its inhibitory effect only in sensitive cell lines with wild-type TP53 [61,75], SL-176 affects the viability of virtually all tested NB and $\mathrm{MB}$ cell lines with $\mathrm{IC}_{50}$ values around $1 \mu \mathrm{M}$, regardless of TP53 mutational status, while non-cancerous cell lines show much lower sensitivity (Figures 4A and S2B) [76]. Admittedly, this stands in contrast to our DepMap findings, where gene dependency on PPM1D clusters to TP53-mutated cell lines. On the other hand, this comprehensive effect is concordant with the results of our PPM1D knockdown results, which prove that PPM1D is essential for NB proliferation even in the TP53-mutated cell line SK-N-BE(2), in vitro and in vivo. Moreover, Ogasawara et al. already showed that SL-176 is effective against the NSCLC cell line NCI-H1299, which lacks p53 expression [49].

Additionally, the p53 modulator RITA — in contrast to Nutlin-3 - exhibited its effect independently of the TP53 mutational status of the neuroblastoma cell lines studied. This finding is consistent with previous observations and it has been suggested that this might be explained by a conformational change in p53 that also pertains to the mutated protein [77]. Thus, differences between susceptibility according to TP53 mutational status have been seen both in p53 modulators and WIP1 inhibitors. From a clinical point of 
view, it is encouraging that WIP1 inhibition can be effective even in TP53-mutated tumors, given that TP53 mutations are often prevalent in recurrent and refractory neuroblastomas. Aberrant expression of PPM1D caused by chromosomal gains, gene amplification or activating mutations has been described in multiple cancers and high expression of PPM1D often correlates with poor patient outcome [78]. Moreover, high expression and/or genetic aberration of PPM1D is frequently found in cancers with wtTP53, suggesting that high protein levels or stability of WIP1 inhibits the activity of p53, which can result in neoplastic transformation and malignant tumor formation $[79,80]$. These data, together with the demonstration that PPM1D-deficient mice show a delayed onset of mammary gland tumor development, whereas overexpression of PPM1D in mice subjected to external DNA stress develop cancers that are highly similar to tumors in p53-deficient mice [81], strongly suggest that PPM1D is an oncogene. Genetic analyses have shown the presence of unbalanced chromosome $17 \mathrm{q}$ gain in $90 \%$ of high-risk neuroblastomas, and high expression of PPM1D is associated with adverse patient outcome [8,12-14,34]. Hence, the majority of high-risk neuroblastoma patients could potentially have benefits from treatment including a WIP1 inhibitor. Chromosome 17q gain or isochromsome 17q is also the most common chromosomal aberration found in medulloblastoma. A total of $30-50 \%$ of primary medulloblastoma contain chromosome 17q gain. The highest expression of PPM1D is observed in Group 3 and Group 4 as well as in metastatic medulloblastomas [28]. PPM1D expression is also associated with worse overall and progression-free survival in patients with these tumors [28,82]. Therefore, WIP1 inhibitors could have potential as a treatment option in Group 3 and Group 4 medulloblastoma patients as well as in SHH patients with wtTP53 expressing high levels of PPM1D.

Here, we show that WIP1 constitutes a druggable target in neuroblastoma and medulloblastoma that should be further developed and evaluated in combination with current treatment modalities and investigated for testing in clinical trials, given the fact that the majority of patients with poor prognosis have aberrant expression of WIP1 [34,82]. It may be argued that targeting DNA repair mechanisms and phosphatase activity in particular seems a problematic hurdle, but our current data are promising proofs of a principle providing molecular and pharmacological evidence. Furthermore, genetic instability and accumulation of genetic aberrations over time are major obstacles in metastatic and relapsing pediatric cancers, further supporting the potential role and impact of WIP1 as a promising therapeutic target for pediatric patients with high-risk neuroblastoma and medulloblastoma, as well as a wide range of adult cancer patients.

Overexpression of PPM1D promotes the growth and treatment resistance of pediatric and adult cancers [19]. Our study together with others has shown that dysregulation of WIP1 is targetable with small-molecule inhibitors [19]. Additionally, compared with conventional chemotherapies, interventions that modulate the activity of WIP1 could provide a more specific option with reduced cytotoxicity. Hence, compounds that inhibit the activity of WIP1 either directly or indirectly should have potential as a treatment option in patients with wtTP53 and aberrant WIP1 expression.

\section{Materials and Methods}

\subsection{Cell Culture and Reagents}

Twenty-two human cell lines of different origin were used throughout the study: eleven neuroblastoma cell lines (IMR-32, Kelly, NB1691, SH-EP, SH-SY5Y, SK-N-AS, SKN-BE(2), SK-N-DZ, SK-N-FI, SK-N-SH, TR14), eight medulloblastoma/sPNET cell lines (DAOY, D283MED, D384MED, D425MED, D458MED, MEB-MED8A, PFSK-1, UW228-3), two breast cancer cell lines (MCF-7, BT-474), and one human fetal lung fibroblast cell line (MRC-5). In addition, one neural multipotent progenitor cell line from mouse (C17.2) was used. The cell lines were purchased from ATCC, except D384MED, D425MED, D458MED, PFSK-1, MEB-MED8A and UW228-3, which were kindly provided by Dr. M. Nistér (Karolinska Institutet), NB1691 and TR14 by Dr. D. Tweddle (Wolfson Childhood Cancer Research Centre, Newcastle University, Newcastle upon Tyne, NE1 7RU, UK) and C17.2 
by Dr. T. Ringstedt (Dept. Woman's and Children's Health, Karolinska Institutet, 171-77 Solna, Sweden).

The cell lines were cultured in RPMI 1640 (IMR-32, Kelly, NB1691, SH-EP, SK-NAS, SK-N-BE(2), SK-N-DZ, SK-N-FI, SK-N-SH, TR14, PFSK-1 and MRC-5), Dulbecco's modified Eagle's medium (DMEM; MEB-MED8A, C17.2, BT-474), Minimum Essential Media (MEM; DAOY, D283MED, D384MED), Richter's improved MEM with zinc/DMEM (IMEMZO/DMEM; D425MED and D458MED), or DMEM/F12 (SH-SY5Y and UW228-3). Medium was supplemented with 10\% (or 15\% for C17.2, MEB-MED8A, D425MED and 20\% for D384MED) heat-inactivated fetal bovine serum (FBS), $2 \mathrm{mM}$ L-glutamine, $100 \mathrm{IU} / \mathrm{mL}$ penicillin G, and $100 \mu \mathrm{g} / \mathrm{mL}$ streptomycin (Life Technologies Inc., Stockholm, Sweden) at $37^{\circ} \mathrm{C}$ in a humidified 5\% $\mathrm{CO}_{2}$ atmosphere. To the MCF-7 and D384MED media, $1 \mathrm{mM}$ sodium pyruvate and $1 \mathrm{mM}$ non-essential amino acids solution (Gibco) were also added. All media were purchased from Gibco BRL.

The identities of the cell lines were verified by short tandem repeat genetic profiling using the AmpFISTR ${ }^{\circledR}$ IdentifilerTM PCR Amplification Kit (Applied Biosystems) in December 2015 and all cell lines were used in passages below 25. All experiments were executed in Opti-MEM (GIBCO) supplemented with glutamine, streptomycin and penicillin (HyClone Thermo Fisher Scientific, Waltham, MA, USA), except transfection experiments, which were performed without antibiotics.

PPM1D-knockdown SK-N-BE(2) cells and corresponding control cells were cultured in selection media (standard media according to above supplemented with $0.5-2 \mu \mathrm{g} / \mathrm{mL}$ puromycin).

RITA and Nutlin-3 were purchased from Cayman Chemical Company and SigmaAldrich, respectively, and SL-176 and SPI-001 were synthesized as described previously [49,51]. RITA and Nutlin-3 were dissolved in DMSO (Sigma-Aldrich), while SL-176 was dissolved in a mix of DMSO (33\%) and ethanol (67\%). Further dilutions were made in Opti-MEM or PBS. The DMSO concentration did not exceed $1 \% \mathrm{v} / \mathrm{v}$ in any experiment. For the in vivo studies, SL-176 was dissolved in a mixture of DMSO (33\%) and ethanol $(67 \%)$ and further diluted in sodium chloride $0.9 \%$.

\subsection{Short Hairpin RNA (shRNA)}

For the transfections, cells were seeded in 6-well plates, left to attach and transfected using Lipofectamine 2000 (Thermo Fisher Scientific) with $4 \mu \mathrm{g}$ of four pre-designed shRNAs (GIPZ Lentiviral) targeting human PPM1D (172_0502-F-1 (Clone ID: V2LHS_262759), 172_0556-D-7 (Clone ID: V2LHS_27794), 172-0447-C-2 (Clone ID: V2LHS_27798) and 172_0496-G-2 (Clone ID: V2LHS_262763), Dharmacon) and non-silencing pGIPZ Lenti Control shRNA (\#RHS4346, Dharmacon). Cells were incubated for $6 \mathrm{~h}$ in the transfection medium, which was then replaced with corresponding culture medium. After $24-48 \mathrm{~h}$, cells were subjected to further analyses. For generating stable transfections, cells were grown in selective medium $(0.5-2 \mu \mathrm{g} / \mathrm{mL}$ puromycin selection).

\subsection{Viability Assays}

For evaluation of the cytotoxic effect on cell viability, we used the colorimetric formazan-based assay WST-1 (Roche), according to the manufacturer's description. Briefly, cells were seeded into 96-well plates (5000-10,000 cells/well), incubated overnight and treated with drugs the following day. After $72 \mathrm{~h}$, WST-1 reagent was added and absorbance was measured at $450 \mathrm{~nm}$. All concentrations were tested in triplicate. The mean out of usually three or more independent experiments is reported.

To determine colony formation, 100 cells/well in the non-exposure experiments and 300 cells/well in the irradiation experiments were seeded in $60 \mathrm{~mm}$ cell+ culture plates (Sarstedt, Sweden) and allowed to attach for $24 \mathrm{~h}$ before exposure to ionizing radiation (Cobolt ${ }^{60}$ source) at 2 or $4 \mathrm{~Gy}$, when applicable. After 10-14 days of incubation in medium, cells were washed, fixed in formaldehyde (4\%), stained with Giemsa (Gibco, BRL Solna, 
Sweden) and colonies ( 1 clone $>50$ cells) with 50\% plate efficiency were manually counted. The mean out of at least three experiments is reported.

Cell viability after PPM1D silencing was assessed by the trypan blue exclusion assay. In brief, cells $\left(4.4 \times 10^{4}\right.$ MEB-MED8A cells/well and $2.5 \times 10^{4}$ SK-N-BE(2) cells/well, respectively) were seeded and transfected in six-well plates, three wells for each time point per cell line and transfection group, and cultured for six days. Cells were then stained with $0.4 \%$ trypan blue (GIBCO, BRL) and viable (unstained) cells were counted daily to determine the total number of living cells. The mean out of three experiments is reported.

\subsection{Irradiation of Human Cancer Cell Lines}

SK-N-BE(2), SH-SY5Y, DAOY, Med8a and MCF-7 cells were seeded into six-well cell culture plates (300,000-500,000 cells/well) in standard medium with 10\% FBS and allowed to attach overnight, with exception for Med8a cells growing in suspension. Prior to treatment, $60-80 \%$ confluency was observed. Medium was removed and replaced with OptiMEM containing a SL-176 concentration equivalent to the corresponding $\mathrm{IC}_{50}$ value for each cell line $(0.5-1.3 \mu \mathrm{M})$. Med8a cells were directly seeded in OptiMEM containing SL-176 at IC 50 . After $1 \mathrm{~h}$ incubation, cells were irradiated with $4 \mathrm{~Gy}$ (Cobolt ${ }^{60}$ source) while kept on ice, after which incubation at $37^{\circ} \mathrm{C}$ continued for the time indicated $(0,4,8$, or $24 \mathrm{~h})$. Cells were harvested using Cell Dissociation Solution Non-enzymatic (Sigma-Aldrich). For the irradiation of the stably transfected SK-N-BE(2) neuroblastoma cell lines (PPM1D shRNA and control shRNA), 500,000 cells/well were seeded into six-well cell culture plates as described above, allowed to attach overnight and irradiated with $2 \mathrm{~Gy}$ and $4 \mathrm{~Gy}$, respectively, and harvested after 48 and $72 \mathrm{~h}$. SK-N-BE(2) non-transfected cells were treated with $40 \mathrm{mM}$ cisplatin and used as a positive control for double-strand DNA breaks.

\subsection{Western Blot}

Protein extraction from cell lysate was performed in RIPA buffer ( $25 \mathrm{mM}$ Tris ( $\mathrm{pH} 7.8)$, $2 \mathrm{mM}$ EDTA, 20\% glycerol, $0.1 \%$ Nonidet P-40 (NP-40), 1 mM dithiothreitol), supplemented with protease inhibitor cocktail (Roche Diagnostic, Basel, Switzerland) and phosphatase inhibitor cocktail 1 (Sigma-Aldrich Solna, Sweden). The protein concentration was measured using Bradford protein assay (Bio-Rad Hercules, CA, USA). A total of $50 \mu \mathrm{g}$ of protein was separated by SDS-PAGE, transferred to nylon membranes (Millipore Inc., Sundbyberg, Sweden) and incubated with antibodies against phosphorylated and total ATM (350 kDa); Wip1 (67 kDa); phosphorylated and total Chk1 (56 kDa) and Chk2 (62 kDa); phosphorylated and total p53 (53 kDa); phosphorylated and total p38 (43 kDa); total p21 (21 kDa); and $\mathrm{y}-\mathrm{H} 2 \mathrm{AX}$ and H2AX (17 kDa). GAPDH (36 kDa) or $\beta$-tubulin $(51 \mathrm{kDa})$ were used as internal controls. Anti-rabbit IgG conjugated with horseradish peroxidase (Cell Signaling) was used for secondary detection and Pierce Super Signal (Pierce) for chemiluminescent visualization. For a full list of antibodies, see Supplementary Table S4.

\subsection{Quantitative Real-Time RT-PCR Analyses}

The mRNA expression levels were quantified using TaqMan ${ }^{\circledR}$ technology on an ABI PRISM 7500 sequence detection system (PE Applied Biosystems). Primers were selected from the Assay-on-Demand products (Applied Biosystems), including human PPM1D (Hs00186230_m1), and 18S ribosomal RNA (Hs99999901_s1). All gene expression assays were designed with an FAM reporter dye at the $5^{\prime}$ end of the TaqMan MGB probe, and a non-fluorescent quencher at the $3^{\prime}$ end of the probe. High-capacity RNA-to-cDNA kit (Applied Biosystems) was used to synthesize cDNA from $100 \mathrm{ng}$ of RNA per sample. The PCR reaction was performed in a total reaction volume of $25 \mu \mathrm{L}$ containing $1 \times$ TaqMan $^{\circledR}$ Universal PCR Master Mix, $1 \times$ TaqMan $^{\circledR}$ Gene Expression Assays (Applied Biosystems) and $10 \mu \mathrm{L}$ of cDNA from each sample as a template, in MicroAmp optical 96-well plates covered with MicroAmp optical caps (Applied Biosystems). Firstly, samples were heated for $2 \mathrm{~min}$ at $50^{\circ} \mathrm{C}$ and then amplified for 40 cycles of $15 \mathrm{~s}$ at $95^{\circ} \mathrm{C}$ and $1 \mathrm{~min}$ at $60^{\circ} \mathrm{C}$. A standard curve was generated for relative quantification with cDNA synthesized from 
$1 \mu \mathrm{g}$ RNA of the cell lines combined. For every sample, the amount of target mRNA was normalized to the standard curve and normalized to $18 \mathrm{~S}$ ribosomal RNA expression. All experiments included a no template control and were performed in triplicate.

\subsection{CRISPR-Cas9 Loss of Function Screening}

The DepMap Public CRISPR (Avana) 18Q3 gene dependency dataset including 485 cancer cell lines (whereof 15 neuroblastoma and 7 medulloblastoma cell lines) as well as mutation call dataset was downloaded from the Broad Institute Cancer Dependency Map (https:/ / depmap.org/portal/, 18Q3, accessed on 5 September 2018) and used for analysis of PPM1D and TP53 genetic vulnerabilities [83]. Visualization and analysis of enriched functional processes associated with TP53 dependency was performed in the Search Tool for the Retrieval of Interacting Genes/Protein (STRING) database [84].

\subsection{Flow Cytometry}

Phosphorylation of H2AX was assayed with Alexa Fluor 647-conjugated anti-phosphoH2AX (2F3, Biolegend, San Diego, CA, USA) at 24 and $72 \mathrm{~h}$ on cells that were transfected with PPM1D-shRNA 172_0502-F-1 and control shRNA, respectively. A minimum of 10,000 events were recorded on Becton-Dickinson FACSCalibur or LSR II flow cytometers (BD Biosciences, San Jose, CA, USA). Data analysis was performed using the Cell Quest software.

\subsection{Ethical Permits}

The animal experiments were approved by the regional ethics committee for animal research in Northern Stockholm, appointed by and under the control of the Swedish Board of Agriculture and the Swedish Court (ethical approvals N304/08 and N391/11). All animal experiments were in accordance with national regulations (SFS 1988:534, SFS 1988:539, and SFS 1988:541).

\subsection{Xenograft Studies}

Immunodeficient nude mice (female 4-6 weeks old, NMRI-nu/nu, Scanbur, Stockholm, Sweden) were used for xenograft studies. The mice were kept under specific pathogen-free conditions at a maximum of six individuals per cage and given sterile water and food ad libitum. All mice were treatment-naïve at the start of the experiment.

Under general anesthesia, each mouse was injected subcutaneously on the rear flank with $10 \times 10^{6}$ SK-N-BE(2) neuroblastoma cells or $17 \times 10^{6}$ DAOY medulloblastoma cells. In the knockdown experiment, mice were inoculated bilaterally with $5 \times 10^{6} \mathrm{SK}-\mathrm{N}-\mathrm{BE}(2)$ cells (clone d) that were knocked down for PPM1D $(n=8)$ and SK-N-BE(2) control cells (clone C) that were transfected with non-silencing shRNA $(n=15)$, respectively, and followed until the tumor reached $0.1 \mathrm{~mL}$.

In the drug treatment experiments, mice with SK-N-BE(2) xenografts were randomly assigned to three different treatment groups when the tumor reached $\geq 0.1 \mathrm{~mL}$. For twelve days, mice received either daily intraperitoneal injections (i.p.) of SL-176 at $3 \mathrm{mg} / \mathrm{kg}(n=8)$ or $0.5 \mathrm{mg} / \mathrm{kg}(n=6)$, or no treatment $(n=6)$. The mean tumor volume at the start of treatment was $0.115 \mathrm{~mL}$.

Mice bearing DAOY xenografts were randomly divided into two different groups, and treatment commenced at tumor volume $\geq 0.12 \mathrm{~mL}$. Mice received either $3 \mathrm{mg} / \mathrm{kg}$ SL-176 as daily i.p. injection for 21 days $(n=8)$, or no treatment $(n=7)$. The mean tumor volume at the start of treatment was $0.124 \mathrm{~mL}$.

In all xenograft-bearing mice, tumors were measured by caliper every day and the animals were monitored for signs of toxicity including weight loss. The tumor volume was estimated as $(\text { width })^{2} \times$ length $\times 0.44$. At sacrifice, tumors were dissected and either frozen or fixed in formaldehyde, for subsequent analyses. 


\subsection{Immunohistochemistry of Xenograft Tumors}

Formalin-fixed and paraffin-embedded tissue sections were deparaffinized in xylene and graded alcohols, hydrated and washed in phosphate-buffered saline (PBS). After antigen retrieval in sodium citrate buffer $(\mathrm{pH} 6)$ in a microwave oven, endogenous peroxidase was blocked by $0.3 \% \mathrm{H}_{2} \mathrm{O}_{2}$ for $15 \mathrm{~min}$. Sections were incubatedovernight at $4{ }^{\circ} \mathrm{C}$ with primary antibody phosphor-histone H2A.X (Ser139) (Cell Sinalling), cleaved caspase-3 (Asp175) (Cell signaling) or Ki67 (SP6, Neomarkers, CA, USA). Anti-rabbithorseradish peroxidase (HRP) was used as secondary antibody. SignalStain Boost kit (Cell Signalling) was used for detection. Matched isotype controls were used as a control for non-specific staining.

\subsection{Statistical Analysis}

Statistical analyses were performed with GraphPad Prism software (GraphPad Software, San Diego, CA, USA). The $\mathrm{IC}_{50}$ values (inhibitory concentration 50\%) were determined from log concentrations-effect curves using non-linear regression analysis. $\mathrm{T}$ test was used to compare means between two groups, and for comparison of three or more groups, one-way ANOVA followed by Bonferroni multiple-comparisons post hoc test were used. Paired analysis was performed with repeated measures ANOVA or, when values were missing, on mixed-effect analysis with Bonferroni multiple-comparisons post hoc test. Survival analysis was examined with log-rank test, and Fisher's test was used to test significance of association between the two categories. Correlations were assessed with Pearson test/Spearman non-parametric test. $p<0.05$ was considered significant and all tests were two-sided. Survival curves were calculated using the Kaplan-Meier method.

\section{Conclusions}

Overexpression of PPM1D is an important tumorigenic factor in medulloblastoma and neuroblastoma, as these tumor cells are highly dependent on high levels of PPM1D for their survival. Compounds that inhibit the activity of WIP1 suppress both neuroblastoma and medulloblastoma growth in mouse xenograft models. Unfortunately, all the WIP1 inhibitors described to date remain non-viable clinically, either due to poor solubility or because of poor pharmacokinetic properties of the compounds in vivo. Since the structure of WIP1 is still unknown, inhibitors of WIP1 have to a large extent been identified through high-throughput screening of chemical libraries [19]. Hence, more specific inhibitors of WIP1 with better bio-availability need to be developed in order to accurately demonstrate the potential of inhibiting WIP1 in patients.

Supplementary Materials: The following are available online at https: / www.mdpi.com/article / 10.3390/cancers13236042/s1, Figure S1: Chromosome 17q copy number gains in medulloblastoma cell lines. Comparative genomic hybridization (CGH) array of five medulloblastomas and one supratentorial primitive neuroectodermal tumor cell line PFSK-1, illustrated as a blue line in single chromosome view. The red and green lines show the strongest and weakest allele intensity, respectively for each cell line. Arrows indicate gain of chromosome 17q. For allele-specific intensity calculations using AsCNAR algorithm, see [42], Figure S2: PPM1D knockdown increases H2AX phosphorylation. $\gamma \mathrm{H} 2 \mathrm{AX}$ was measured with flow cytometry 24 and $72 \mathrm{~h}$ after transfection with shRNA against PPM1D or control shRNA, Figure S3: The WIP1 phosphatase inhibitor SL-176 suppresses neuroblastoma and medulloblastoma viability. A. Dose-response curves for cell viability after $72 \mathrm{~h}$ of treatment with three WIP1 inhibitors; SL-176, SPI-001 or CCT007093, in neuroblastoma cell lines and breast cancer cell line MCF-7. Cell viability was determined using WST-1 assays. Data represent the mean \pm S.E.M. of at least three experiments. B. Dose-response curves for cell viability after $72 \mathrm{~h}$ of treatment with SL-176, RITA or Nutlin-3 in neuroblastoma cell lines, medulloblastoma cell lines, the sPNET cell line PFSK-1 and the breast cancer cell line MCF-7. The fibroblast cell line MRC-5 and the murine neural progenitor cell line C17.2 were used as non-tumorigenic controls for drug toxicity. Cell viability was determined with WST-1. Data represent the mean \pm S.E.M. of at least three experiments, Figure S4: Original western blots (Figure 3). Table S1: TP53 wild-type neuroblastoma cell lines displayed a higher genetic dependency of PPM1D as compared to TP53 mutated cell lines, 
Table S2: IC50 values for WIP1 inhibitors, RITA and Nutlin-3, Table S3: TP53 mutational status in the cell lines used in the study, Table S4: List of antibodies used for Western blotting.

Author Contributions: Conceptualization, J.I.J., P.K., and J.M.; methodology, J.M., D.T., S.F., B.S., N.E., M.W., and G.G.-O.; validation, J.M., D.T., S.F., B.S., N.E., M.W., G.G.-O., P.K., and J.I.J.; formal analysis, J.M., D.T., S.F., and M.W.; investigation, J.M., D.T., S.F., B.S., N.E., and M.W.; resources, K.T., K.S., P.K., and J.I.J.; data curation, J.M., D.T., S.F., and M.W.; writing-original draft preparation, J.M. and J.I.J.; writing-review and editing, J.M., D.T., M.W., P.K., and J.I.J. visualization, J.M., D.T., S.F., T.M., B.S., M.W., and G.G.-O.; supervision, T.M., P.K., and J.I.J.; project administration, J.M., P.K., and J.I.J.; funding acquisition, P.K. and J.I.J. All authors have read and agreed to the published version of the manuscript.

Funding: This research was funded by the Swedish Childhood Cancer Foundation, the Swedish Research Council, the Swedish Cancer Foundation, the Swedish Foundation for Strategic Research, Karolinska Institutet, Märta and Gunnar V Philipson Foundation, The Cancer Research Foundations of and the Photo-excitonix Project at Hokkaido University. The APC was funded by the Swedish Cancer Foundation (grant no.: CAN2018/460, J.I. Johnsen).

Institutional Review Board Statement: The study was conducted according to the guidelines of the Declaration of Helsinki, and approved by the regional ethics committee for animal research in Northern Stockholm, appointed by and under the control of the Swedish Board of Agriculture and the Swedish Court. All animal experiments were in accordance with national regulations (SFS 1988:534, SFS 1988:539, and SFS 1988:541).

Informed Consent Statement: Not applicable.

Data Availability Statement: The data presented in this study are available on request from the corresponding author. The data are not publicly available due to privacy.

Acknowledgments: This work was supported with grants from the Swedish Childhood Cancer Foundation, the Swedish Research Council, the Swedish Cancer Foundation, the Swedish Foundation for Strategic Research, Karolinska Institutet, Märta and Gunnar V Philipson Foundation, The Cancer Research Foundations of Radiumhemmet and and the Photo-excitonix Project at Hokkaido University. The study sponsors had no role in the design of the study; the collection, analysis, and interpretation of the data; the writing of the manuscript; or the decision to submit the manuscript for publication. All grant suppliers have consented to be acknowledged.

Conflicts of Interest: The authors have no conflict of interest to declare.

\section{References}

1. Hanahan, D.; Weinberg, R.A. Hallmarks of Cancer: The next Generation. Cell 2011, 144, 646-674. [CrossRef] [PubMed]

2. Hafner, A.; Bulyk, M.L.; Jambhekar, A.; Lahav, G. The Multiple Mechanisms That Regulate P53 Activity and Cell Fate. Nat. Rev. Mol. Cell Biol. 2019, 20, 199-210. [CrossRef]

3. Bykov, V.J.N.; Eriksson, S.E.; Bianchi, J.; Wiman, K.G. Targeting Mutant P53 for Efficient Cancer Therapy. Nat. Rev. Cancer 2018, 18, 89-102. [CrossRef]

4. Martin, B.; Verdebout, J.-M.; Mascaux, C.; Paesmans, M.; Rouas, G.; Verhest, A.; Ninane, V.; Sculier, J.-P. Expression of P53 in Preneoplastic and Early Neoplastic Bronchial Lesions. Oncol. Rep. 2002, 9, 223-229. [CrossRef]

5. Gröbner, S.N.; Worst, B.C.; Weischenfeldt, J.; Buchhalter, I.; Kleinheinz, K.; Rudneva, V.A.; Johann, P.D.; Balasubramanian, G.P.; Segura-Wang, M.; Brabetz, S.; et al. The Landscape of Genomic Alterations across Childhood Cancers. Nature 2018, 555, 321-327. [CrossRef]

6. Carr-Wilkinson, J.; O'Toole, K.; Wood, K.M.; Challen, C.C.; Baker, A.G.; Board, J.R.; Evans, L.; Cole, M.; Cheung, N.-K.V.; Boos, J.; et al. High Frequency of P53/MDM2/P14ARF Pathway Abnormalities in Relapsed Neuroblastoma. Clin. Cancer Res. 2010, 16, 1108-1118. [CrossRef] [PubMed]

7. Ramaswamy, V.; Remke, M.; Adamski, J.; Bartels, U.; Tabori, U.; Wang, X.; Huang, A.; Hawkins, C.; Mabbott, D.; Laperriere, N.; et al. Medulloblastoma Subgroup-Specific Outcomes in Irradiated Children: Who Are the True High-Risk Patients? Neuro Oncol. 2016, 18, 291-297. [CrossRef] [PubMed]

8. Bown, N.; Cotterill, S.; Lastowska, M.; O’Neill, S.; Pearson, A.D.; Plantaz, D.; Meddeb, M.; Danglot, G.; Brinkschmidt, C.; Christiansen, H.; et al. Gain of Chromosome Arm 17q and Adverse Outcome in Patients with Neuroblastoma. N. Engl. J. Med. 1999, 340, 1954-1961. [CrossRef] [PubMed]

9. Abel, F.; Ejeskär, K.; Kogner, P.; Martinsson, T. Gain of Chromosome Arm 17q Is Associated with Unfavourable Prognosis in Neuroblastoma, but Does Not Involve Mutations in the Somatostatin Receptor 2 (SSTR2) Gene at 17q24. Br. J. Cancer 1999, 81, 1402-1409. [CrossRef] 
10. Gilbert, F.; Feder, M.; Balaban, G.; Brangman, D.; Lurie, D.K.; Podolsky, R.; Rinaldt, V.; Vinikoor, N.; Weisband, J. Human Neuroblastomas and Abnormalities of Chromosomes 1 and 17. Cancer Res. 1984, 44, 5444-5449.

11. Theissen, J.; Oberthuer, A.; Hombach, A.; Volland, R.; Hertwig, F.; Fischer, M.; Spitz, R.; Zapatka, M.; Brors, B.; Ortmann, M.; et al. Chromosome 17/17q Gain and Unaltered Profiles in High Resolution Array-CGH Are Prognostically Informative in Neuroblastoma. Genes Chromosomes Cancer 2014, 53, 639-649. [CrossRef]

12. Łastowska, M.; Cotterill, S.; Pearson, A.D.J.; Roberts, P.; McGuckin, A.; Lewis, I.; Bown, N. Gain of Chromosome Arm 17q Predicts Unfavourable Outcome in Neuroblastoma Patients. Eur. J. Cancer 1997, 33, 1627-1633. [CrossRef]

13. Meddeb, M.; Danglot, G.; Chudoba, I.; Vénuat, A.M.; Bénard, J.; Avet-Loiseau, H.; Vasseur, B.; Le Paslier, D.; Terrier-Lacombe, M.J.; Hartmann, O.; et al. Additional Copies of a $25 \mathrm{Mb}$ Chromosomal Region Originating from 17q23.1-17qter Are Present in 90\% of High-Grade Neuroblastomas. Genes Chromosomes Cancer 1996, 17, 156-165. [CrossRef]

14. Plantaz, D.; Mohapatra, G.; Matthay, K.K.; Pellarin, M.; Seeger, R.C.; Feuerstein, B.G. Gain of Chromosome 17 Is the Most Frequent Abnormality Detected in Neuroblastoma by Comparative Genomic Hybridization. Am. J. Pathol 1997, 150, 81-89. [PubMed]

15. Biegel, J.A.; Rorke, L.B.; Packer, R.J.; Sutton, L.N.; Schut, L.; Bonner, K.; Emanuel, B.S. Isochromosome 17q in Primitive Neuroectodermal Tumors of the Central Nervous System. Genes Chromosomes Cancer 1989, 1, 139-147. [CrossRef] [PubMed]

16. Bien-Willner, G.A.; Mitra, R.D. Mutation and Expression Analysis in Medulloblastoma Yields Prognostic Variants and a Putative Mechanism of Disease for I17q Tumors. Acta Neuropathol. Commun. 2014, 2, 74. [CrossRef] [PubMed]

17. Bigner, S.H.; Mark, J.; Friedman, H.S.; Biegel, J.A.; Bigner, D.D. Structural Chromosomal Abnormalities in Human Medulloblastoma. Cancer Genet. Cytogenet. 1988, 30, 91-101. [CrossRef]

18. Griffin, C.A.; Hawkins, A.L.; Packer, R.J.; Rorke, L.B.; Emanuel, B.S. Chromosome Abnormalities in Pediatric Brain Tumors. Cancer Res. 1988, 48, 175-180.

19. Nahta, R.; Castellino, R.C. Phosphatase Magnesium-Dependent $1 \delta$ (PPM1D), Serine/Threonine Protein Phosphatase and Novel Pharmacological Target in Cancer. Biochem. Pharmacol. 2021, 184, 114362. [CrossRef]

20. Fiscella, M.; Zhang, H.; Fan, S.; Sakaguchi, K.; Shen, S.; Mercer, W.E.; Woude, G.F.V.; O'Connor, P.M.; Appella, E. Wip1, a Novel Human Protein Phosphatase That Is Induced in Response to Ionizing Radiation in a P53-Dependent Manner. Proc. Natl. Acad. Sci. USA 1997, 94, 6048-6053. [CrossRef] [PubMed]

21. Kamada, R.; Kudoh, F.; Ito, S.; Tani, I.; Janairo, J.I.B.; Omichinski, J.G.; Sakaguchi, K. Metal-Dependent Ser/Thr Protein Phosphatase PPM Family: Evolution, Structures, Diseases and Inhibitors. Pharmacol. Ther. 2020, 215, 107622. [CrossRef]

22. Fujimoto, H.; Onishi, N.; Kato, N.; Takekawa, M.; Xu, X.Z.; Kosugi, A.; Kondo, T.; Imamura, M.; Oishi, I.; Yoda, A.; et al. Regulation of the Antioncogenic Chk2 Kinase by the Oncogenic Wip1 Phosphatase. Cell Death Differ. 2006, 13, 1170-1180. [CrossRef]

23. Lu, X.; Nannenga, B.; Donehower, L.A. PPM1D Dephosphorylates Chk1 and P53 and Abrogates Cell Cycle Checkpoints. Genes Dev. 2005, 19, 1162-1174. [CrossRef]

24. Lu, X.; Nguyen, T.-A.; Donehower, L.A. Reversal of the ATM/ATR-Mediated DNA Damage Response by the Oncogenic Phosphatase PPM1D. Cell Cycle 2005, 4, 1060-1064. [CrossRef]

25. Oliva-Trastoy, M.; Berthonaud, V.; Chevalier, A.; Ducrot, C.; Marsolier-Kergoat, M.-C.; Mann, C.; Leteurtre, F. The Wip1 Phosphatase (PPM1D) Antagonizes Activation of the Chk2 Tumour Suppressor Kinase. Oncogene 2007, 26, 1449-1458. [CrossRef]

26. Shreeram, S.; Hee, W.K.; Demidov, O.N.; Kek, C.; Yamaguchi, H.; Fornace, A.J.; Anderson, C.W.; Appella, E.; Bulavin, D.V. Regulation of ATM/P53-Dependent Suppression of Myc-Induced Lymphomas by Wip1 Phosphatase. J. Exp. Med. 2006, 203, 2793-2799. [CrossRef] [PubMed]

27. Yoda, H.; Inoue, T.; Shinozaki, Y.; Lin, J.; Watanabe, T.; Koshikawa, N.; Takatori, A.; Nagase, H. Direct Targeting of MYCN Gene Amplification by Site-Specific DNA Alkylation in Neuroblastoma. Cancer Res. 2019, 79, 830-840. [CrossRef] [PubMed]

28. Castellino, R.C.; De Bortoli, M.; Lu, X.; Moon, S.-H.; Nguyen, T.-A.; Shepard, M.A.; Rao, P.H.; Donehower, L.A.; Kim, J.Y.H. Medulloblastomas Overexpress the P53-Inactivating Oncogene WIP1/PPM1D. J. Neurooncol. 2008, 86, 245-256. [CrossRef]

29. Fuku, T.; Semba, S.; Yutori, H.; Yokozaki, H. Increased Wild-Type P53-Induced Phosphatase 1 (Wip1 or PPM1D) Expression Correlated with Downregulation of Checkpoint Kinase 2 in Human Gastric Carcinoma. Pathol. Int. 2007, 57, 566-571. [CrossRef]

30. Hirasawa, A.; Saito-Ohara, F.; Inoue, J.; Aoki, D.; Susumu, N.; Yokoyama, T.; Nozawa, S.; Inazawa, J.; Imoto, I. Association of 17q21-Q24 Gain in Ovarian Clear Cell Adenocarcinomas with Poor Prognosis and Identification of PPM1D and APPBP2 as Likely Amplification Targets. Clin. Cancer Res. 2003, 9, 1995-2004. [PubMed]

31. Lambros, M.B.; Natrajan, R.; Geyer, F.C.; Lopez-Garcia, M.A.; Dedes, K.J.; Savage, K.; Lacroix-Triki, M.; Jones, R.L.; Lord, C.J.; Linardopoulos, S.; et al. PPM1D Gene Amplification and Overexpression in Breast Cancer: A QRT-PCR and Chromogenic in Situ Hybridization Study. Mod. Pathol. 2010, 23, 1334-1345. [CrossRef]

32. Nikbakht, H.; Panditharatna, E.; Mikael, L.G.; Li, R.; Gayden, T.; Osmond, M.; Ho, C.-Y.; Kambhampati, M.; Hwang, E.I.; Faury, D.; et al. Spatial and Temporal Homogeneity of Driver Mutations in Diffuse Intrinsic Pontine Glioma. Nat. Commun. 2016, 7, 11185. [CrossRef]

33. Ruark, E.; Snape, K.; Humburg, P.; Loveday, C.; Bajrami, I.; Brough, R.; Rodrigues, D.N.; Renwick, A.; Seal, S.; Ramsay, E.; et al. Mosaic PPM1D Mutations Are Associated with Predisposition to Breast and Ovarian Cancer. Nature 2013, 493, 406-410. [CrossRef]

34. Saito-Ohara, F.; Imoto, I.; Inoue, J.; Hosoi, H.; Nakagawara, A.; Sugimoto, T.; Inazawa, J. PPM1D Is a Potential Target for 17q Gain in Neuroblastoma. Cancer Res. 2003, 63, 1876-1883. [PubMed] 
35. Tan, D.S.P.; Lambros, M.B.K.; Rayter, S.; Natrajan, R.; Vatcheva, R.; Gao, Q.; Marchiò, C.; Geyer, F.C.; Savage, K.; Parry, S.; et al. PPM1D Is a Potential Therapeutic Target in Ovarian Clear Cell Carcinomas. Clin. Cancer Res. 2009, 15, 2269-2280. [CrossRef] [PubMed]

36. Xie, M.; Lu, C.; Wang, J.; McLellan, M.D.; Johnson, K.J.; Wendl, M.C.; McMichael, J.F.; Schmidt, H.K.; Yellapantula, V.; Miller, C.A.; et al. Age-Related Mutations Associated with Clonal Hematopoietic Expansion and Malignancies. Nat. Med. 2014, 20, 1472-1478. [CrossRef] [PubMed]

37. Zhang, L.; Chen, L.H.; Wan, H.; Yang, R.; Wang, Z.; Feng, J.; Yang, S.; Jones, S.; Wang, S.; Zhou, W.; et al. Exome Sequencing Identifies Somatic Gain-of-Function PPM1D Mutations in Brainstem Gliomas. Nat. Genet. 2014, 46, 726-730. [CrossRef]

38. Bulavin, D.V.; Phillips, C.; Nannenga, B.; Timofeev, O.; Donehower, L.A.; Anderson, C.W.; Appella, E.; Fornace, A.J. Inactivation of the Wip1 Phosphatase Inhibits Mammary Tumorigenesis through P38 MAPK-Mediated Activation of the P16Ink4a-P19Arf Pathway. Nat. Genet. 2004, 36, 343-350. [CrossRef]

39. Doucette, T.A.; Yang, Y.; Pedone, C.; Kim, J.Y.H.; Dubuc, A.; Northcott, P.D.; Taylor, M.D.; Fults, D.W.; Rao, G. WIP1 Enhances Tumor Formation in a Sonic Hedgehog-Dependent Model of Medulloblastoma. Neurosurgery 2012, 70, 1003-1010. [CrossRef]

40. Demidov, O.N.; Timofeev, O.; Lwin, H.N.Y.; Kek, C.; Appella, E.; Bulavin, D.V. Wip1 Phosphatase Regulates P53-Dependent Apoptosis of Stem Cells and Tumorigenesis in the Mouse Intestine. Cell Stem Cell 2007, 1, 180-190. [CrossRef] [PubMed]

41. Zhang, X.; Wan, G.; Mlotshwa, S.; Vance, V.; Berger, F.G.; Chen, H.; Lu, X. Oncogenic Wip1 Phosphatase Is Inhibited by MiR-16 in the DNA Damage Signaling Pathway. Cancer Res. 2010, 70, 7176-7186. [CrossRef]

42. Kryh, H.; Caren, H.; Erichsen, J.; Sjoberg, R.-M.; Abrahamsson, J.; Kogner, P.; Martinsson, T. Comprehensive SNP Array Study of Frequently Used Neuroblastoma Cell Lines; Copy Neutral Loss of Heterozygosity Is Common in the Cell Lines but Uncommon in Primary Tumors. BMC Genom. 2011, 12, 443. [CrossRef] [PubMed]

43. Schleiermacher, G.; Raynal, V.; Janoueix-Lerosey, I.; Combaret, V.; Aurias, A.; Delattre, O. Variety and Complexity of Chromosome 17 Translocations in Neuroblastoma. Genes Chromosomes Cancer 2004, 39, 143-150. [CrossRef] [PubMed]

44. Aguirre, A.J.; Meyers, R.M.; Weir, B.A.; Vazquez, F.; Zhang, C.-Z.; Ben-David, U.; Cook, A.; Ha, G.; Harrington, W.F.; Doshi, M.B.; et al. Genomic Copy Number Dictates a Gene-Independent Cell Response to CRISPR-Cas9 Targeting. Cancer Discov. 2016, 6, 914-929. [CrossRef]

45. Carén, H.; Kryh, H.; Nethander, M.; Sjöberg, R.-M.; Träger, C.; Nilsson, S.; Abrahamsson, J.; Kogner, P.; Martinsson, T. High-Risk Neuroblastoma Tumors with 11q-Deletion Display a Poor Prognostic, Chromosome Instability Phenotype with Later Onset. Proc. Natl. Acad. Sci. USA 2010, 107, 4323-4328. [CrossRef]

46. Northcott, P.A.; Robinson, G.W.; Kratz, C.P.; Mabbott, D.J.; Pomeroy, S.L.; Clifford, S.C.; Rutkowski, S.; Ellison, D.W.; Malkin, D.; Taylor, M.D.; et al. Medulloblastoma. Nat. Rev. Dis Primers 2019, 5, 1-20. [CrossRef] [PubMed]

47. Gilmartin, A.G.; Faitg, T.H.; Richter, M.; Groy, A.; Seefeld, M.A.; Darcy, M.G.; Peng, X.; Federowicz, K.; Yang, J.; Zhang, S.-Y.; et al. Allosteric Wip1 Phosphatase Inhibition through Flap-Subdomain Interaction. Nat. Chem. Biol. 2014, 10, 181-187. [CrossRef]

48. Kozakai, Y.; Kamada, R.; Kiyota, Y.; Yoshimura, F.; Tanino, K.; Sakaguchi, K. Inhibition of C-Terminal Truncated PPM1D Enhances the Effect of Doxorubicin on Cell Viability in Human Colorectal Carcinoma Cell Line. Bioorg. Med. Chem. Lett. 2014, 24, 5593-5596. [CrossRef]

49. Ogasawara, S.; Kiyota, Y.; Chuman, Y.; Kowata, A.; Yoshimura, F.; Tanino, K.; Kamada, R.; Sakaguchi, K. Novel Inhibitors Targeting PPM1D Phosphatase Potently Suppress Cancer Cell Proliferation. Bioorg. Med. Chem. 2015, 23, 6246-6249. [CrossRef]

50. Rayter, S.; Elliott, R.; Travers, J.; Rowlands, M.G.; Richardson, T.B.; Boxall, K.; Jones, K.; Linardopoulos, S.; Workman, P.; Aherne, W.; et al. A Chemical Inhibitor of PPM1D That Selectively Kills Cells Overexpressing PPM1D. Oncogene 2008, 27, 1036-1044. [CrossRef]

51. Yagi, H.; Chuman, Y.; Kozakai, Y.; Imagawa, T.; Takahashi, Y.; Yoshimura, F.; Tanino, K.; Sakaguchi, K. A Small Molecule Inhibitor of P53-Inducible Protein Phosphatase PPM1D. Bioorg. Med. Chem. Lett. 2012, 22, 729-732. [CrossRef] [PubMed]

52. Northcott, P.A.; Lee, C.; Zichner, T.; Stütz, A.M.; Erkek, S.; Kawauchi, D.; Shih, D.J.; Hovestadt, V.; Zapatka, M.; Sturm, D.; et al. Enhancer Hijacking Activates GFI1 Family Oncogenes in Medulloblastoma. Nature 2014, 511, 428-434. [CrossRef] [PubMed]

53. Bouska, A.; McKeithan, T.W.; Deffenbacher, K.E.; Lachel, C.; Wright, G.W.; Iqbal, J.; Smith, L.M.; Zhang, W.; Kucuk, C.; Rinaldi, A.; et al. Genome-Wide Copy-Number Analyses Reveal Genomic Abnormalities Involved in Transformation of Follicular Lymphoma. Blood 2014, 123, 1681-1690. [CrossRef] [PubMed]

54. Carless, M.A.; Griffiths, L.R. Cytogenetics of Melanoma and Nonmelanoma Skin Cancer. Adv. Exp. Med. Biol. 2014, 810, 160-181. [CrossRef]

55. Herou, E.; Biloglav, A.; Johansson, B.; Paulsson, K. Partial 17q Gain Resulting from Isochromosomes, Unbalanced Translocations and Complex Rearrangements Is Associated with Gene Overexpression, Older Age and Shorter Overall Survival in High Hyperdiploid Childhood Acute Lymphoblastic Leukemia. Leukemia 2013, 27, 493-496. [CrossRef]

56. Malouf, G.G.; Monzon, F.A.; Couturier, J.; Molinié, V.; Escudier, B.; Camparo, P.; Su, X.; Yao, H.; Tamboli, P.; Lopez-Terrada, D.; et al. Genomic Heterogeneity of Translocation Renal Cell Carcinoma. Clin. Cancer Res. 2013, 19, 4673-4684. [CrossRef]

57. Sunpaweravong, P.; Thu, K.L.; Lam, W.L.; Mai, S. Assessment of the Clinical Relevance of 17q25.3 Copy Number and ThreeDimensional Telomere Organization in Non-Small Lung Cancer Patients. J. Cancer Res. Clin. Oncol. 2016, 142, 749-756. [CrossRef]

58. Xiang, D.-B.; Wei, B.; Abraham, S.C.; Huo, L.; Albarracin, C.T.; Zhang, H.; Babiera, G.; Caudle, A.S.; Akay, C.L.; Rao, P.; et al Molecular Cytogenetic Characterization of Mammary Neuroendocrine Carcinoma. Hum. Pathol. 2014, 45, 1951-1956. [CrossRef] 
59. Cardoso, M.; Paulo, P.; Maia, S.; Teixeira, M.R. Truncating and Missense PPM1D Mutations in Early-Onset and/or Familial/Hereditary Prostate Cancer Patients. Genes Chromosomes Cancer 2016, 55, 954-961. [CrossRef]

60. Kahn, J.D.; Miller, P.G.; Silver, A.J.; Sellar, R.S.; Bhatt, S.; Gibson, C.; McConkey, M.; Adams, D.; Mar, B.; Mertins, P.; et al. PPM1D-Truncating Mutations Confer Resistance to Chemotherapy and Sensitivity to PPM1D Inhibition in Hematopoietic Cells. Blood 2018, 132, 1095-1105. [CrossRef]

61. Richter, M.; Dayaram, T.; Gilmartin, A.G.; Ganji, G.; Pemmasani, S.K.; Van Der Key, H.; Shohet, J.M.; Donehower, L.A.; Kumar, R. WIP1 Phosphatase as a Potential Therapeutic Target in Neuroblastoma. PLoS ONE 2015, 10, e0115635. [CrossRef] [PubMed]

62. Wen, J.; Lee, J.; Malhotra, A.; Nahta, R.; Arnold, A.R.; Buss, M.C.; Brown, B.D.; Maier, C.; Kenney, A.M.; Remke, M.; et al. WIP1 Modulates Responsiveness to Sonic Hedgehog Signaling in Neuronal Precursor Cells and Medulloblastoma. Oncogene 2016, 35, 5552-5564. [CrossRef] [PubMed]

63. Shiloh, Y. ATM and Related Protein Kinases: Safeguarding Genome Integrity. Nat. Rev. Cancer 2003, 3, 155-168. [CrossRef]

64. Uyanik, B.; Grigorash, B.B.; Goloudina, A.R.; Demidov, O.N. DNA Damage-Induced Phosphatase Wip1 in Regulation of Hematopoiesis, Immune System and Inflammation. Cell Death Discov. 2017, 3, 1-5. [CrossRef] [PubMed]

65. Yoda, A.; Xu, X.Z.; Onishi, N.; Toyoshima, K.; Fujimoto, H.; Kato, N.; Oishi, I.; Kondo, T.; Minami, Y. Intrinsic Kinase Activity and SQ/TQ Domain of Chk2 Kinase as Well as N-Terminal Domain of Wip1 Phosphatase Are Required for Regulation of Chk2 by Wip1. J. Biol. Chem. 2006, 281, 24847-24862. [CrossRef] [PubMed]

66. Adesina, A.M.; Nalbantoglu, J.; Cavenee, W.K. P53 Gene Mutation and Mdm2 Gene Amplification Are Uncommon in Medulloblastoma. Cancer Res. 1994, 54, 5649-5651.

67. Brodeur, G.M. Neuroblastoma: Biological Insights into a Clinical Enigma. Nat. Rev. Cancer 2003, 3, 203-216. [CrossRef]

68. Matthay, K.K.; Maris, J.M.; Schleiermacher, G.; Nakagawara, A.; Mackall, C.L.; Diller, L.; Weiss, W.A. Neuroblastoma. Nat. Rev. Dis. Primers 2016, 2, 16078. [CrossRef] [PubMed]

69. Saylors, R.L.; Sidransky, D.; Friedman, H.S.; Bigner, S.H.; Bigner, D.D.; Vogelstein, B.; Brodeur, G.M. Infrequent P53 Gene Mutations in Medulloblastomas. Cancer Res. 1991, 51, 4721-4723.

70. Chesler, L.; Goldenberg, D.D.; Collins, R.; Grimmer, M.; Kim, G.E.; Tihan, T.; Nguyen, K.; Yakovenko, S.; Matthay, K.K.; Weiss, W.A. Chemotherapy-Induced Apoptosis in a Transgenic Model of Neuroblastoma Proceeds Through P53 Induction. Neoplasia 2008, 10, 1268-1274. [CrossRef] [PubMed]

71. Weiss, W.A.; Aldape, K.; Mohapatra, G.; Feuerstein, B.G.; Bishop, J.M. Targeted Expression of MYCN Causes Neuroblastoma in Transgenic Mice. EMBO J. 1997, 16, 2985-2995. [CrossRef] [PubMed]

72. Wetmore, C.; Eberhart, D.E.; Curran, T. Loss of P53 but Not ARF Accelerates Medulloblastoma in Mice Heterozygous for Patched. Cancer Res. 2001, 61, 513-516.

73. Issaeva, N.; Bozko, P.; Enge, M.; Protopopova, M.; Verhoef, L.G.G.C.; Masucci, M.; Pramanik, A.; Selivanova, G. Small Molecule RITA Binds to P53, Blocks P53-HDM-2 Interaction and Activates P53 Function in Tumors. Nat. Med. 2004, 10, 1321-1328. [CrossRef] [PubMed]

74. Khoo, K.H.; Verma, C.S.; Lane, D.P. Drugging the P53 Pathway: Understanding the Route to Clinical Efficacy. Nat. Rev. Drug Discov. 2014, 13, 217-236. [CrossRef]

75. Esfandiari, A.; Hawthorne, T.A.; Nakjang, S.; Lunec, J. Chemical Inhibition of Wild-Type P53-Induced Phosphatase 1 (WIP1/PPM1D) by GSK2830371 Potentiates the Sensitivity to MDM2 Inhibitors in a P53-Dependent Manner. Mol. Cancer 2016, 15, 379-391. [CrossRef] [PubMed]

76. Kamada, R.; Kimura, N.; Yoshimura, F.; Tanino, K.; Sakaguchi, K. Inhibition of Lipid Droplet Formation by Ser/Thr Protein Phosphatase PPM1D Inhibitor, SL-176. PLoS ONE 2019, 14, e0212682. [CrossRef]

77. Burmakin, M.; Shi, Y.; Hedström, E.; Kogner, P.; Selivanova, G. Dual Targeting of Wild-Type and Mutant P53 by Small Molecule RITA Results in the Inhibition of N-Myc and Key Survival Oncogenes and Kills Neuroblastoma Cells In Vivo and In Vitro. Clin. Cancer Res. 2013, 19, 5092-5103. [CrossRef]

78. Oghabi Bakhshaiesh, T.; Majidzadeh, A.K.; Esmaeili, R. Wip1: A Candidate Phosphatase for Cancer Diagnosis and Treatment. DNA Repair 2017, 54, 63-66. [CrossRef]

79. Dudgeon, C.; Shreeram, S.; Tanoue, K.; Mazur, S.J.; Sayadi, A.; Robinson, R.C.; Appella, E.; Bulavin, D.V. Genetic Variants and Mutations of PPM1D Control the Response to DNA Damage. Cell Cycle 2013, 12, 2656-2664. [CrossRef] [PubMed]

80. Kleiblova, P.; Shaltiel, I.A.; Benada, J.; Ševčík, J.; Pecháčková, S.; Pohlreich, P.; Voest, E.E.; Dundr, P.; Bartek, J.; Kleibl, Z.; et al. Gain-of-Function Mutations of PPM1D/Wip1 Impair the P53-Dependent G1 Checkpoint. J. Cell Biol. 2013, 201, 511-521. [CrossRef]

81. Milosevic, J.; Fransson, S.; Gulyas, M.; Olsen, T.K.; Gallo-Oller, G.; Treis, D.; Elfman, L.H.M.; Wilhelm, M.; Martinsson, T.; Baryawno, N.; et al. High Expression of PPM1D Induces Tumors Phenotypically Similar to TP53 Loss-of-Function Mutations in Mice. Cancers 2021, 13, 5493. [CrossRef] [PubMed]

82. Buss, M.C.; Remke, M.; Lee, J.; Gandhi, K.; Schniederjan, M.J.; Kool, M.; Northcott, P.A.; Pfister, S.M.; Taylor, M.D.; Castellino, R.C. The WIP1 Oncogene Promotes Progression and Invasion of Aggressive Medulloblastoma Variants. Oncogene 2015, 34, 1126-1140. [CrossRef] [PubMed] 
83. Meyers, R.M.; Bryan, J.G.; McFarland, J.M.; Weir, B.A.; Sizemore, A.E.; Xu, H.; Dharia, N.V.; Montgomery, P.G.; Cowley, G.S.; Pantel, S.; et al. Computational Correction of Copy Number Effect Improves Specificity of CRISPR-Cas9 Essentiality Screens in Cancer Cells. Nat. Genet. 2017, 49, 1779-1784. [CrossRef] [PubMed]

84. Szklarczyk, D.; Morris, J.H.; Cook, H.; Kuhn, M.; Wyder, S.; Simonovic, M.; Santos, A.; Doncheva, N.T.; Roth, A.; Bork, P.; et al. The STRING Database in 2017: Quality-Controlled Protein-Protein Association Networks, Made Broadly Accessible. Nucleic Acids Res. 2017, 45, D362-D368. [CrossRef] 